\title{
La epigrafía de El Palomar de Oliete: cultura escrita en un poblado ibérico
}

\section{Epigraphy at El Palomar de Oliete (Teruel, Spain): literacy of an Iberian settlement}

La epigrafía ibérica se concentra en las ciudades, pero en El Palomar de Oliete (Teruel), un poblado de menos de una hectárea, se ha recuperado un conjunto significativo de inscripciones sobre instrumenta. El objetivo de este trabajo es valorar la cultura escrita de este emplazamiento.

Palabras clave: instrumentum inscriptum, fusayola, grafitos sobre cerámica, cultura escrita.
Although Iberian epigraphy is concentrated in cities, a significant number of inscriptions were discovered at the small settlement of El Palomar (Oliete, Teruel). The aim of this paper is to evaluate the level of literacy of this settlement.

Keywords: instrumentum inscriptum, spindle whorl, inscriptions on pottery, literacy. 


\section{Epigrafía y ciudad}

Es difícil valorar la cultura escrita de sociedades antiguas como la etrusca, la gala o la ibérica. La epigrafía atestigua que emplearon sistemas de escritura propios para anotar sus lenguas, pero no han gozado de una tradición manuscrita milenaria como la romana y la griega que haya permitido conservar sus obras literarias. Por ello, las inscripciones son la principal fuente de información sobre este particular, aunque también es revelador el estudio de los instrumentos de escritura que, hasta ahora, casi no se han tenido en cuenta. ${ }^{1}$ En este trabajo, tomando como ejemplo las inscripciones del yacimiento ibérico de El Palomar de Oliete (Teruel), pretendemos abordar la naturaleza y rango de los yacimientos de los que proceden los textos, un aspecto igualmente marginado por la investigación. En este caso concreto se pretende subrayar la estrecha relación entre ciudad y epigrafía, pero también la excepcionalidad a este respecto de El Palomar. ${ }^{2}$ Tradicionalmente, el estudio de la epigrafía clásica se ha centrado en las inscripciones monumentales, grabadas sobre bronce y piedra, que representan un fenómeno fundamentalmente urbano, y, por contra, ha dedicado una menor atención tanto a las inscripciones del territorio -menos numerosas y entre las que son infrecuentes los epígrafes honoríficos $-{ }^{3}$ como a aquellas que aparecen sobre el instrumentum, en el que han de incluirse el conjunto de los textos de El Palomar, pues todos ellos están realizados sobre objetos cerámicos. Este último tipo de inscripciones ha sido generalmente infravalorado, ${ }^{4}$ pero resultan muy significativas para nuestro propósito, pues informan de una práctica escrita en buena medida espontánea, cotidiana y de ámbito doméstico - frente a la solemnidad de la epigrafía en piedra y bronce- así como relativa a los alfareros en aquellas realizadas antes de la cocción de la cerámica. ${ }^{5}$

La asociación entre escritura y ciudad parece evidente también en la cultura ibérica, ${ }^{6}$ pues los principales conjuntos epigráficos proceden de yacimientos a los que se otorga rango politano, ya sea porque aparecen citados en las fuentes clásicas como tales, porque acuñaron moneda o porque su urbanismo, extensión y el análisis espacial permiten corroborar que fueron núcleos significativos, que jerarquizaron el poblamiento de una comarca. ${ }^{7}$ Por su parte, la historia de la epigrafía ibérica puede dividirse en dos grandes periodos: el primero comprende desde

1. Sobre este aspecto es seminal el artículo de Božič y Feugère (2004).

2. Para los contextos arqueológicos de los que proceden las inscripciones ibéricas, véase Simón (2012a) y Bonet (2013).

3. Véanse, no obstante, las actas del congreso L'epigrafia del villaggio (Calbi et al. 1993).

4. Sin embargo, en los últimos decenios se observa un creciente interés, como demuestran las actas de los congresos de Instrumenta inscripta latina y de la asociación Ductus.

5. Sobre la epigrafía paleohispánica en cerámica puede verse De Hoz (2007), Simón (2013: 543-564), Beltrán et al. (e. p.).

6. Sobre esta asociación entre epigrafía y ciudad: Beltrán (2005).

7. Sobre este particular y relativo a Aragón, véase Asensio (1995). los documentos más antiguos (siglo v a. C.) hasta la Segunda Guerra Púnica y el segundo coincide con la conquista y dominación romanas, al menos, hasta el reinado de Augusto, cuando desaparecen las inscripciones ibéricas. ${ }^{8} \mathrm{Su}$ asociación con el mundo urbano se atestigua desde el primer periodo, aunque en este momento inicial se reduce a la franja litoral (Panosa 1999: 51-75; De Hoz 2011: cap. 4), donde destacan los conjuntos epigráficos de yacimientos como el Puig de Sant Andreu (Ullastret, C.2 = BDH: GI.15), Ensérune (B.1 = BDH: HER.02) y Pech Maho (B.8 $=B D H$ : AUD.05), ${ }^{9}$ todos ellos de gran relevancia e identificados como ciudades, aunque de ninguno de los tres se conoce su nombre antiguo. Esta misma circunstancia se mantiene en época romana, incluso se incrementa, pues a partir de la Segunda Guerra Púnica muchas de las ciudades emiten moneda con su propio nombre, en las que son casi las únicas inscripciones de carácter público de la epigrafía ibérica. ${ }^{10}$

Sagunto (F.11 = BDH: V.04) cuenta con una documentación especialmente rica y ofrece por ello un ejemplo ilustrativo de cómo la epigrafía y, por tanto, presumiblemente también el conjunto de la práctica escrita, se concentra en los núcleos urbanos, aunque no en exclusiva. ${ }^{11}$ La mayoría de las inscripciones proceden de la propia ciudad —emplazada en el Castillo de Sagunto, que acuñó moneda desde fecha temprana y que cuenta con el conjunto de epigrafía lapídea más importante del mundo ibérico- y no de su territorium, aunque hay algunas excepciones muy significativas. ${ }^{12} \mathrm{La}$ primera la representa el plomo recuperado en el Grau Vell, el puerto de la ciudad, que por su cronología (siglo $\mathrm{V}$ a. C.) puede considerarse la inscripción saguntina más antigua (Aranegui y Vives-Ferrándiz 2006) (Cf. Ferrer et al. 20142016: 135-136). La segunda excepción es el santuario de Montaña Frontera, del que procede un conjunto de pequeños pedestales inscritos y cuyo carácter religioso es incuestionable (Simón 2012c)..$^{13}$ Este último es un ejemplo excepcional en ámbito ibérico, aunque puede compararse con los esgrafiados rupestres, a los que se suele otorgar un carácter sacro y cuya ubicación es igualmente rural, principalmente en paredes de abrigos naturales. ${ }^{14}$

Un segundo ejemplo pertinente lo ofrece Burriac, oppidum ibérico que se identifica con la ceca de ilturo (A.11 = $B D H$ : MON.11), cuya epigrafía ha sido objeto de un reciente estudio de conjunto (Sinner y Ferrer 2016). En el yacimiento se ha recuperado más de una treintena de inscripciones, todas ellas sobre cerámica, pero también se han hallado, aunque en

8. Sobre esta periodización, véase De Hoz (1995) y Simón (2013a).

9 Las inscripciones ibéricas se citan según $M L H$ y el Banco de Datos Hesperia (http://hesperia.ucm.es/).

10. Sobre la moneda ibérica $M L H$ I y $D C P H$.

11. Sobre el desarrollo de las ciudades en esta región, véase la reciente síntesis de Bonet et al. (2015).

12. Sobre Sagunto, véase la monografía de Aranegui (2004), sobre su epigrafía: F.11, Velaza (2002) y Simón (2013: 72-88); para el territorium: Martí (1998).

13. Sobre la epigrafía religiosa ibérica: Velaza (2012).

14 Un catálogo de la epigrafía paleohispánica rupestre en Alfayé (2009: Anexo 1); el conjunto más sobresaliente es el de La Cerdaña, en proceso de edición (Campmajo y Ferrer 2010). 
menor número, esgrafiados en sus necrópolis: Can Rodon y Turó dels dos Pins, así como entre el material exhumado en un próximo campo de silos, localizado entre Can Miralles, Can Modolell y Can Bartomeu.

Por su parte, el yacimiento del Tossal de San Miguel de Liria (Valencia; F.13 = BDH: 0.6), que se identifica con la antigua Edeta, se singulariza por su conjunto de tituli picti, realizados sobre la cerámica con decoración pintada y figurada (F.3; Bonet 1995: 449-464). El mayor número proviene de este yacimiento, cabecera del valle medio del Turia (Bonet 1995: 464, 517; Mata 1997: 21). En esta comarca se han localizado otros establecimientos de menor tamaño, identificados como aldeas y fortines dependientes de San Miguel. En estos últimos también se han recuperado tituli picti, aunque son hallazgos excepcionales y casi los únicos epígrafes conocidos en estos lugares: La Monravana, Los Villaricos y Torre Seca, de cada uno de los cuales procede un único titulus pictus (F.12.1= BDH: V.06.005, F.16.1= $B D H$ : V.05.01 y F.25.1 = BDH: V.02.01) $;^{15}$ el Castellet de Bernabé, en el que se han recuperado dos tituli picti (Sarrión $2003=B D H$ : V.06.002-003) y un plomo (Guérin y Silgo $1996=B D H$ : V.06.001); y El Puntal dels Llops, con un grafito grabado sobre un objeto realizado con asta de ciervo (Bonet y Mata 2002: 165, fig. $120=B D H$ : V.03.01).${ }^{16} \mathrm{El}$ grueso de los tituli proviene, por tanto, del lugar central (unos setenta ejemplares), del yacimiento de San Miguel de Liria, mientras que de los establecimientos secundarios solo proceden hallazgos aislados que, incluso, se ha interpretado como importaciones procedentes de la propia Edeta (Mata 1997: 33, fig. I.13).

\section{El valle medio del Ebro}

Son varios los criterios para reconocer el rango politano a un yacimiento, los principales es que sea mencionado como tal por las fuentes escritas, que acuñe moneda y que presente una notable extensión. Estrictamente arqueológico es el último criterio, aunque relativo, ya que depende del tamaño de los yacimientos en una región y periodo concretos, así como la jerarquización de los mismos y el control del territorio circundante, aspecto sobre el que el aporte de la llamada Arqueología Espacial ha sido fundamental, desarrollada para el valle del Ebro y Celtiberia especialmente por parte de F. Burillo. ${ }^{17}$ Debe añadirse a los argumentos anteriores, la presencia de edificios públicos, las defensas - principalmente murallas- y el urbanismo. En el noreste peninsular los yacimientos de diez hectáreas o mayores son excepcionales, en el valle medio del Ebro tan solo unos pocos, como El Cabezo de las Minas (Botorrita), La Caridad (Caminreal) o La Corona (Fuentes de Ebro), alcanzan tal tamaño. Asensio (1995: 43-51) considera

15. En el caso de La Monravana hay otra marca monolítera igualmente pintada (Fletcher 1972: 117, lám. 7.2).

16. Sobre el territorio de Edeta, uid. Mata (2001).

17. Véase su monografía sobre los celtíberos: Burillo (2007: esp. 251-267), también Burillo (2009, 2011, 2011a, con toda su bibliografía anterior); a partir principalmente de las fuentes escritas: Fatás (1980-1981). Para el conjunto del ámbito ibérico, pueden verse los trabajos recopilados en Belarte et al. (2015). esta última cifra excesiva para determinar si estamos o no ante una ciudad, ya que en el área predominan los núcleos más pequeños a los que, no obstante, se les puede atribuir rango politano, como sucede con El Palao de Alcañiz, cuya superficie se estima ocupa entre 3 y 4 hectáreas. F. Burillo (2011a: 285) también reconoce el pequeño tamaño de los oppida en esta región, con unas dimensiones muy similares entre sí, que por término medio oscilan entre las 4,5 y 10 hectáreas.

En lo que respecta a la epigrafía, en el valle medio del Ebro solo se atestigua en la segunda de las fases ya descritas, pues no hay ningún texto que con seguridad sea anterior al siglo II a. C. La difusión de la epigrafía en esta región puede considerarse coetánea a la conquista romana ${ }^{18}$ y es el Castelillo de Alloza el yacimiento con el corpus (grafitos y tituli picti sobre cerámica, $M L H$ III: E. 4 = BDH: TE.06) de cronología más temprana, ya que su final se sitúa a mediados del siglo II a. C. 19

Las inscripciones también se concentran, como sucede en el levante, en las ciudades. Puede reseñarse los conjuntos procedentes de Salduie -bajo el actual casco urbano de Zaragoza (BDH: Z.10) (Galve 1996; Asensio 1995: 95-99; Fatás y Beltrán 1997) — y especialmente el de Azaila $\left(\right.$ E.1 = BDH: TE.02) ${ }^{20}$ Este último es el único yacimiento de su rango excavado casi en su totalidad, al menos, la zona de la llamada acrópolis, ${ }^{21}$ pero aún así sorprende el elevado número de inscripciones ibéricas que ha proporcionado, pues el corpus rebasa los cuatrocientos cincuenta ejemplares, de hecho, es el conjunto local más numeroso de todo el mundo ibérico. Todas ellas son inscripciones sobre instrumenta, principalmente cerámica, aunque también aparecen sobre un conjunto de pesas de telar alabastrinas. Sobre las cerámicas descubiertas en el lugar, locales e importadas, se documentan sellos, tituli picti y principalmente esgrafiados post cocturam, en su mayoría breves o brevísimos, que comparecen con predilección sobre cerámica helenística de barniz negro (campaniense), ánforas, pesas de telar y fusayolas. El conjunto ejemplifica bien la cultura epigráfica de la región, en la que predominan los esgrafiados sobre cerámica, mientras que están ausentes los plomos (a diferencia de lo que ocurre en la costa) y solo hay un pequeño grupo de inscripciones sobre piedra (E.10.1 = BDH: TE.15.01 y E.13.1-2 $=B D H:$ Z.16-01-02). ${ }^{22}$ Por último, se encuentran las

18. Solo pudiera ser anterior un esgrafiado sobre un adobe de San Antonio de Calaceite (E.11.1 = BDH: TE.14.01, Simón 2012: n. ${ }^{\circ} 1$ ), pues su destrucción parece producirse a fines del siglo III a. C. (Moret 2005: 280). Sobre la epigrafía de esta región en este periodo: Beltrán (1995, 2003), Ruiz y Simón (2012). Para la cultura ibérica en el valle medio del Ebro: Beltrán (1996), y sobre la conquista romana: Beltrán et al (2000) y los artículos del monográfico del AEspA dirigido por F. Pina (2003), "Ciudad y Romanización en el Valle Medio del Ebro (siglos II y I a. C.)".

19. CAT: 103-105, sobre el yacimiento también: Loscos et al. (2007).

20. Sobre este yacimiento: M. Beltrán (1976, 1995, 2013).

21. Sobre la extensión del yacimiento: Asensio (1995: 151-157).

22. Los plomos inscritos hallados más al interior provienen del valle del Segre, el ejemplo más occidental es una lámina que parece provenir de San Esteban de la Litera (Huesca), en el Cinca (Ferrer y Garcés $2005=$ BDH: HU.03.01). 


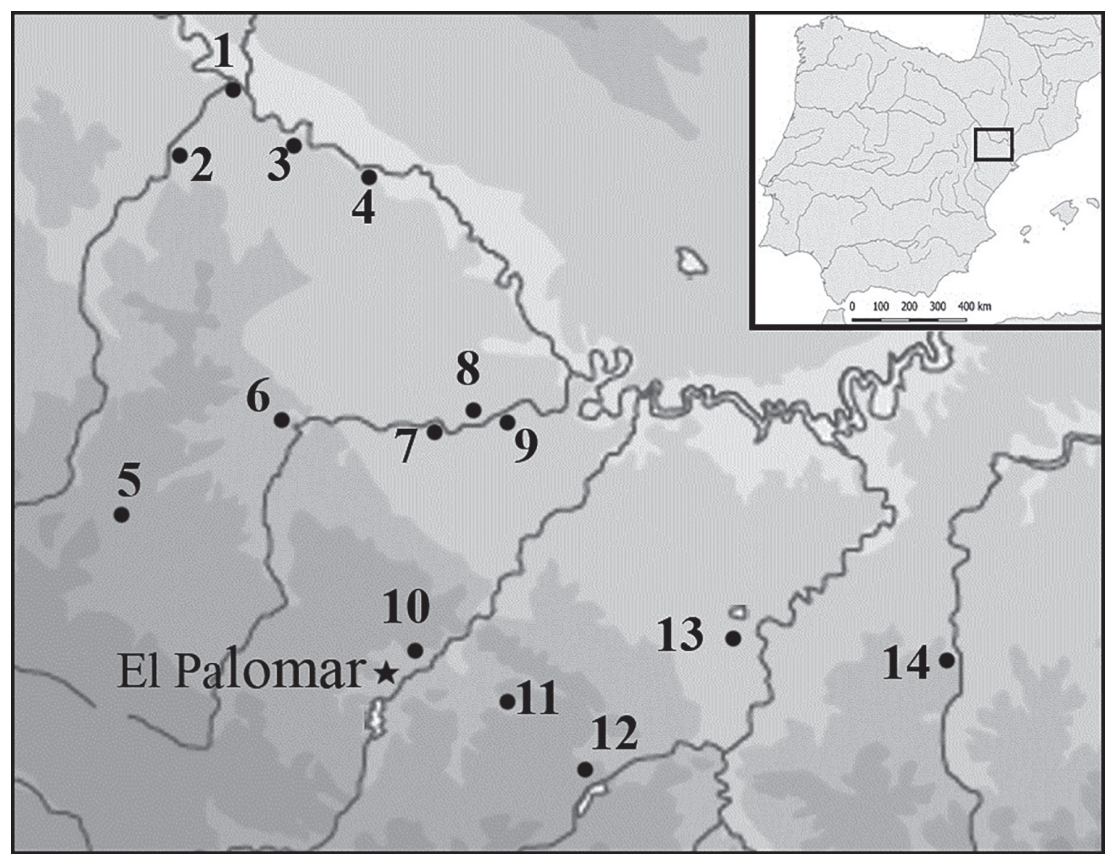

Figura. 1. Localización del Palomar (Oliete) y otros yacimientos importantes coetáneos y/o citados en el texto: 1. Zaragoza (Salduie), 2. Cabezo de las Minas (Contrebia Belaisca), 3. La Cabañeta (El Burgo de Ebro), 4. La Corona (Fuentes de Ebro), 5. Los Castellares, Herrera de los Navarros, 6. Lécera, 7. Cabezo de la Bovina (Vinaceite), 8. Val de Alegre 1 (Azaila), 9. El Cabezo de Alcalá (Azaila), 10. San Pedro (Oliete), 11. El Castelillo (Alloza), 12. La Guardia (Alcorisa), 13. El Palao (Alcañiz), 14. Torre Cremada (Valdetormo).

cecas sedetanas, que L. Villaronga (2004: 185-189) identifica como un grupo con personalidad propia debido a su iconografía: anverso con cabeza varonil imberbe rodeada de tres delfines y jinete con palma en el reverso. Incluye en este grupo a iltukoite (A.20 $=B D H:$ MON.20), kelse (A.21 = BDH: MON.21), otobeśken (A.23 = BDH: MON.23), seteisken (A.25 $=B D H:$ MON.25), lakine (A.22 = BDH: MON.22) y saltuie (A.24 $=B D H$ : MON.24).

\section{El Palomar de Oliete}

El Palomar de Oliete es una interesante excepción $(\mathrm{E} .5=B D H$ : TE.05), pues se trata de un pequeño poblado de 0,8 hectáreas del que proviene un grupo significativo de inscripciones, que permiten valorar la difusión y uso de la escritura en los asentamientos de tipo menor que se localizan en los territoria de las ciudades. ${ }^{23}$

Este yacimiento se ubica en la orilla izquierda del río Martín, sobre los restos de una de las terrazas fluviales y a un kilómetro del actual pueblo de Oliete. Se conoce desde antiguo, pues J. Cabré (1911) ya lo recoge en su inédito Catálogo Monumental de Teruel (vol. 1) y D. J. Trallero, el farmacéutico del pueblo, realizó algunas catas a comienzos del siglo xx (Beltrán 1958: 27-28). D. J. Galiay (1951) llevó a cabo tres campañas de excavación en la década de los cuarenta, en las que desenterró cuatro calles y parte

23. Sobre este tipo de yacimientos en el valle medio del Ebro, véase la recopilación de Asensio (1995: 323-328). de una vivienda, trabajos sobre los que solo publicó una sucinta nota. ${ }^{24}$ A. Beltrán (1958) reseñó parte de los materiales de esta intervención (conservados en el Museo de Zaragoza) en el artículo que dedica a las piezas de la colección Orensanz provenientes del Palomar. Por último, el Museo de Teruel acometió campañas de excavación y consolidación entre los años 1977 y 1981, durante las que se realizó el estudio del espacio delimitado por las mencionadas calles (figura 2). La manzana exhumada se compone por una treintena de estancias que se agrupan en once casas y, además, cuatro almacenes de planta rectangular y con entrada independiente; en algunas se conservan escaleras, lo que asegura la existencia de un segundo piso. Lo que se ha exhumado de su urbanismo permite reconocer una trama regular, con calles enlosadas y perpendiculares que delimitan manzanas rectangulares. Dicha regularidad presupone una planificación previa, que también se atestigua por la existencia de muros comunes a varias viviendas, así como por la ligera inclinación de las calles para la evacuación de aguas y el ensanchamiento en el cruce de algunas de estas vías a modo de plaza (Vicente et al. 1990: 12-13; Vicente 2007: 187).

Se publicaron informes sobre el progreso de las excavaciones en la revista Teruel (Vicente 1981, 1982). En este periodo también se editó la carta arqueológica de la provincia, realizada por los responsables de

24. Estas excavaciones también fueron reseñadas por Ripoll (1955: 122-124, figura 1), quien también comenta algunos materiales que descubrió en su visita al lugar. 


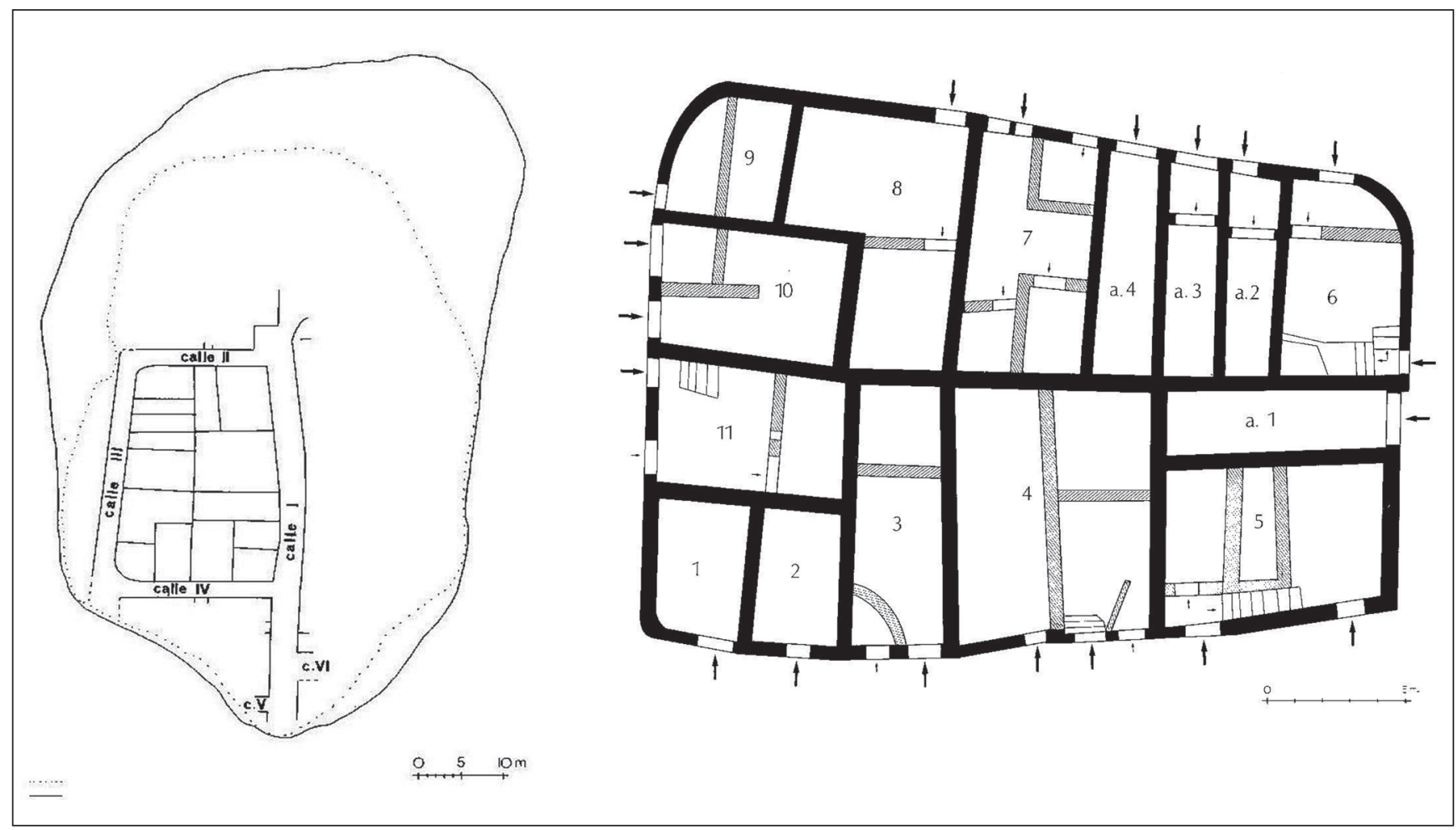

Figura 2. Planta de El Palomar, Oliete, y detalle de la manzana I, excavada por el Museo de Teruel (Vicente et al. 1990).

las excavaciones en Oliete y que incluye una entrada sobre El Palomar (CAT: n. ${ }^{\circ}$ 409). Finalmente, se celebró una exposición en la localidad con los materiales más sobresalientes recuperados en el yacimiento y un catálogo de la misma, que incluye un estudio general y fichas de 148 piezas (Vicente et al. 1990). ${ }^{25}$ Sin embargo, nunca se han llegado a publicar por completo los resultados ni el conjunto de materiales, aunque Jaime Vicente (2007) dedica un capítulo al yacimiento en el catálogo de la exposición Fragmentos de historia. 100 años de arqueología en Teruel. En él ofrece una descripción general y resume las principales conclusiones de sus excavaciones: se trata de un asentamiento agrícola construido en el siglo III a. C. sobre una terraza del río Martín, no amurallado, aunque un foso circunda el pequeño cerro que ocupa, y destruido durante las guerras sertorianas, tras lo que no se ocupó excepto como necrópolis en época visigoda. Está parcialmente arrasado a consecuencia de la extracción de gravas, pero se estima que ocupó una superficie de 0,8 hectáreas. ${ }^{26}$

Por lo reducido de su tamaño parece inverosímil que fuese una ceca (Asensio 1995: 82), aunque se ha propuesto identificarlo con iltukoite, a partir de la vaga semejanza entre la leyenda y el topónimo actual (A.20 = BDH: MON.20) (Beltrán 1958: 32; $\mathrm{CNH}$ :

25. Esta es la información que maneja Asensio (1995: 235324) para el escueto comentario que dedica al yacimiento.

26. Sobre los niveles de destrucción de época sertoriana en el valle del Ebro: Beltrán (2002); para esta etapa también se puede consultar la monografía de Barrandon (2011).
255-256). ${ }^{27}$ Quizá fuese dependiente del yacimiento del Cabezo de San Pedro de los Griegos o Torrejón de los Moros, igualmente ubicado en la margen izquierda del río Martín y también sito en el hodierno término municipal de Oliete. También parece que fue destruido en el primer cuarto del siglo i a. C. (CAT: n. ${ }^{\circ}$ 410) y se trata de un hábitat con unas notabilísimas fortificaciones, pues en su extremo meridional se aprecia una doble línea de foso, lienzos de murallas realizados con grandes sillares escuadrados y varios torreones circulares. ${ }^{28}$ Sin embargo, sus dimensiones tampoco parecen alcanzar las propias de una ciudad, de modo que J. A. Asensio (1995: 326) lo califica como "castillo de montaña".

\section{Inscripciones de El Palomar}

Untermann cataloga cinco inscripciones de El Palomar en su corpus de la epigrafía ibérica (E.5 = $B D H$ : TE.05), parte de las cuales se conocían desde antiguo. Juan Cabré (1911: figura 134, 4 y 5) recoge el dibujo de dos vasos con esgrafiados en una lámina de su inédito Catálogo Monumental de Teruel, que describe como "vasos de cerámica del Altillo [término con el que denomina al yacimiento] con caracteres

27. Las monedas aparecidas en el yacimiento corresponden a otras cecas, mayoritariamente bolśkan (Vicente et al. 1990: 30). El topónimo de Oliete también se ha relacionado con la mansio de Iologum mencionada en el Ravenate (310, 13; Magallón 1987: 222-224).

28. Véase al respecto Vicente et al. (1985), Moret (1996: n. ${ }^{\circ}$ 153), Vicente (2007a). 
ibéricos"; a partir de los dibujos se pueden leer como to $\mathrm{y}$ bato, respectivamente, grabado el primero sobre una taza y el segundo sobre un jarrito. ${ }^{29}$

M. Gómez Moreno (1948: 46) publica el dibujo de dos inscripciones que provienen de este yacimiento, cuyo conocimiento debe a Fidel Fita (figura 3). Para Antonio Beltrán (1958: 32) la procedencia de El Palomar debe darse por segura, "porque la noticia debe proceder de Trallero o Vives", el primero de los cuales, farmacéutico de la localidad, realizó catas en el yacimiento por encargo del segundo. Sin embargo, la descripción que Gómez Moreno ofrece sobre estos dos epígrafes, cuyo paradero se desconoce, es la siguiente: "una nota manuscrita del P. Fita consigna que en término de este pueblo (Oliete), a los pies de la torre de S. Pedro y masada de Garaya, se descubren innumerables restos de cerámica con letras ibéricas; y allí mismo van dibujados con descuido, preparando su estudio, estos dos letreros, que reproduzco a título de simple noticia”. Efectivamente, el autor no ofrece lectura sino simplemente el dibujo de ambas inscripciones que, por la descripción que hace de ellas, es más probable que provengan de San Pedro de los Griegos, otro yacimiento ibérico ya mencionado e igualmente sito en el término municipal de Oliete. ${ }^{30}$

Gómez Moreno no ofrece sino el dibujo de los grafitos, para los que M. Beltrán (1976: 313) propuso las siguientes lecturas: binḿ(s?)lurenḿ y arblsa+ba. Posteriormente, Untermann los recogió en MLH, E.5.3 y $4,{ }^{31}$ en el primer caso lee binkiśaúrenḿn[i], donde están subrayados los signos difíciles de reconocer en el dibujo de Fita y en los que precisamente estriban las discrepancias respecto a la interpretación de Beltrán. El final en ḿ del primer texto es atípico y, por ello, Untermann propone reconstruir $-\mathbf{m}[\mathbf{i}]($ E.5.3 $=B D H$ : TE.05.03), una partícula posesiva bien documentada en ibérico y que suele ocupar la posición final en las fórmulas de propiedad (MLH III-1: § 534). Precediéndole se puede identificar otro morfo (-en), igualmente recurrente en ibérico tras nombres personales y que también parece servir para indicar la posesión (MLH III-1: § 521). Por tanto, lo más plausible es que la primera parte de la inscripción recoja un nombre personal, en el que pueden identificarse los formantes auŕ (MLH III-1: § 7.21, Rodríguez Ramos 2014: n. ${ }^{\circ}$ 20) y bin (MLH III-1: $\S ~ 7.40$, Rodríguez Ramos 2014: n. $\left.{ }^{\circ} 47\right) .^{32}$

29. Es posible que el primero sea una taza de la colección Trallero (Vicente et al. 1990: n. ${ }^{\circ} 70$ ).

30. Se han dado diversas noticias de la recuperación de inscripciones ibéricas en este yacimiento que, sin embargo, nunca han llegado a publicarse. La más antigua aparece en sucinta reseña en el Boletín de la Real Academia de la Historia (1883: 210), en la que se informa que D. Emilio Burges, en el lugar conocido como Solana Emilia, cerca de San Pedro, descubrió lo que se describen como "inscripciones ibéricas en estampillas de cerámica”. No es completamente claro si Beltrán (1958: 27) se refiere a El Palomar o a San Pedro cuando indica que "Ortego también realizó hallazgos de cerámica ibérica campaniense: un tiesto con un grafito ibérico que se lee il”. En la CAT, n. ${ }^{\circ} 410$ se indica que se halló un "pondus con el grafito l”, presumiblemente el descrito por Orensanz (1975-1976: 177) como "un trozo de pondus con el signo V".

31. BDH: TE.05.03-04.

32. Faria (1994: 67) lo interpreta como un antropónimo trimembre: bin-kiś-auŕ.

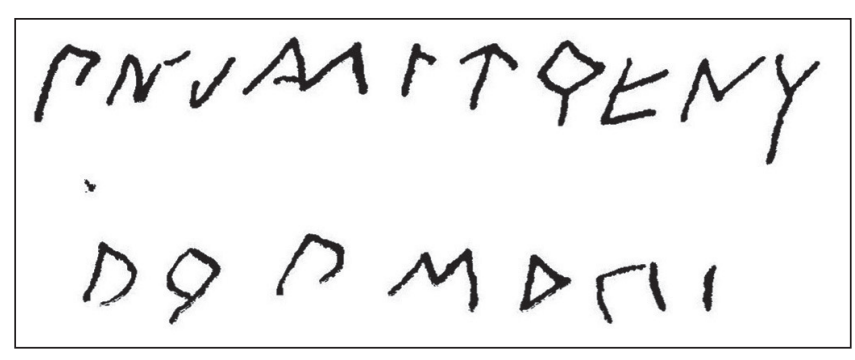

Figura 3. Dibujos de inscripciones de Oliete según Fita, transmitidos por Gómez Moreno (1948: 298).

Para el segundo epígrafe propone la lectura arbiśkaŕ, que puede identificarse como un nombre personal, pues sería tocayo del padre de uno de los jinetes de la turma Salluitana: Arbiscar (CIL I ${ }^{2}$ 709). ${ }^{33}$ Sin embargo, es evidente que la lectura de los últimos signos es completamente libre e inspirada por el paralelo que ofrece el bronce ascolitano pues, si nos atenemos al dibujo, la lectura debería ser arbiśabiba, en la que incluso cabría la posibilidad de reconocer los dos últimos signos como numerales; no obstante, la falta de paralelos induce a pensar que el dibujo no trasmite correctamente el epígrafe. Es imposible, aunque el texto coincida parcialmente (pudiera tratarse del mismo antropónimo), que sea la inscripción grabada sobre una pesa de telar que se comentará más adelante, tal y como sostiene L. Silgo (1999: 28; 2001: 348), ${ }^{34}$ pues esta última fue recuperada en las excavaciones que el Museo de Teruel realizó en El Palomar durante los años setenta y ochenta del siglo xx. Pudieran ser dos inscripciones de propiedad de un mismo individuo, pero tampoco parece probable si tenemos en cuenta que la sucinta información de Fita, transmitida por Gómez Moreno, apunta a que pudiera proceder de otro yacimiento de la localidad, el ya mencionado Cabezo de San Pedro. Sí es reseñable que en el citado epígrafe (E.5.4 = $B D H$ : TE.05.04) se lea: arbiśkaŕr+, un posible NP que parece compartir el primer formante con este otro grafito.

En el artículo que Antonio Beltrán (1958: 31, figuras 20 y 27) dedica al yacimiento y a los materiales que proceden del mismo y pertenecientes a la colección Orensanz, reseña la existencia de pesas de telar con "letras be, e, l", de las que no ofrece más comentario, aunque sí añade un dibujo. La más interesante es el ejemplar que lleva impreso un sello (Beltrán 1958: 31, figura 27) y que es recogido por Untermann como E.5.5 (BDH: TE.05.01, figura 4) (Salvat 2005: n. ${ }^{\circ}$ 49; Simón 2008: 263; 2013: EP3). ${ }^{35}$ La estampilla es rectangular y comprende dos únicos signos unidos en nexo: 'bim' $\mathrm{y}$, aunque Untermann no excluye la lectura biu, es preferible la primera. Destaca el uso del signo m, poco común (MLH III-1: 253) y que parece propio de las inscripciones ibéricas arcaicas (Maluquer 1968: 32-33), de hecho, Rodríguez Ramos (2004: 128) estima su uso como indicio de

33. MLH III-1: § 7.13 y 64; Rodríguez Ramos (2014: n. ${ }^{\circ} 11$ y 69).

34. HEp 11, n. ${ }^{\circ}$ 545; Moncunill (2007: 186).

35. BDH: TE.05.05. 


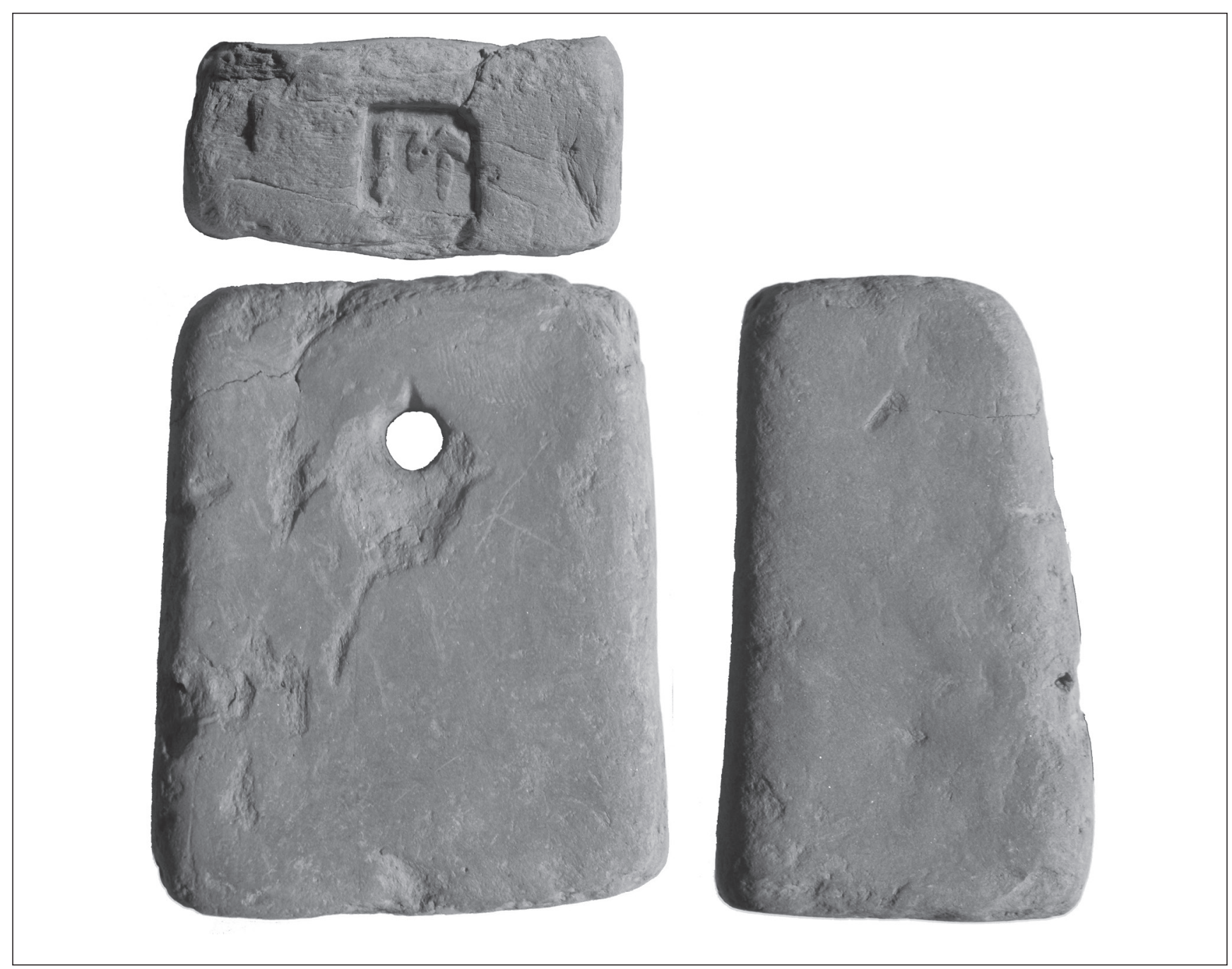

Figura 4. Pesa de telar con sello de El Palomar (Museo de Teruel).

una cronología anterior al 175 a. C., aunque señala algunos ejemplos de fecha posterior, como el epígrafe que nos ocupa y dos grafitos idénticos (tim) sobre sendas cerámicas campanienses de Azaila (E.1.224 y 225 = BDH: TE.02.224-225). También pertenecía a la colección Orensanz un jarrito con el grafito le (Vicente et al. 1990: n. ${ }^{\circ}$ 64). ${ }^{36}$

Posteriormente, Atrián (1968) ${ }^{37}$ publicó una inscripción sobre un olpe (figura 5) recuperado de forma casual por un grupo local de colegialas y que se conserva completo, junto a él también fueron descubiertas dos pesas de telar de gran tamaño, la mayor de las cuales llevaba inciso un signo ti (Atrián 1968). El epígrafe está grabado post coc-

36. Hay un formante onomástico ibérico que presenta dicho inicio: leis, MLH III-1: § 7.85, Rodríguez Ramos 2014: n. ${ }^{\circ} 97$.

37. También está recogida en Vicente et al. (1990: n. ${ }^{\circ}$ 94) y en el catálogo de Fragmentos de Historia, p. 320. No es una forma propia los repertorios de cerámica ibérica (Vegas 1973: 88, tipo 38), que aparece en la región por primera vez en contextos de época sertoriana (Aguarod 2017: 59-61) y que en latín se denominan lagoena (Hilgers 1969: 61-65, n. ${ }^{\circ}$ 205) nombre que aparece en algunas inscripciones latinas de propiedad grabadas sobre esta clase de recipientes (Binsfeld 1997: n. $\left.{ }^{\circ} 1-16\right)$. turam sobre los hombros de la pieza y presenta varios puntos de lectura conflictiva, pues la forma del cuarto signo es singular y puede interpretarse bien como bo o bien como ta (Cf. Ferrer 2005: nota 20), y el décimo signo, por su parte, que Untermann propone leer, con dudas, como e, es en realidad dos trazos que se unen conformando un ángulo y que se sitúan sobre el resto de grafemas. La posibilidad de reconocerlo como e se apoya en el paralelo que ofrece un epígrafe grabado sobre un recipiente de plata proveniente de Santisteban del Puerto (H.3.4 $=B D H$ : J.02.04): TERCINOI.EGVAN.OSAI.F. Para la pieza del Palomar, Untermann baraja las lecturas: eikeboŕenmiekuan y eiketaŕenmíekuan. ${ }^{38}$ En la parte central del texto es posible reconocer los morfos ibéricos -en y -mí, bien documentados y que, por norma, aparecen pospuestos a un nombre personal conformando una fórmula para indicar la propiedad del objeto inscrito (MLH III-1: § 521 y 534), al que quizá se refiera ekuan (o kuan), que pudiera ser un apelativo del léxico común. Por su parte, en el

38. Atrián (1968) lee eiketaŕenḿikuan, Vicente et al. (1990: n. ${ }^{\circ}$ 94) ikeboŕen mikuan. 


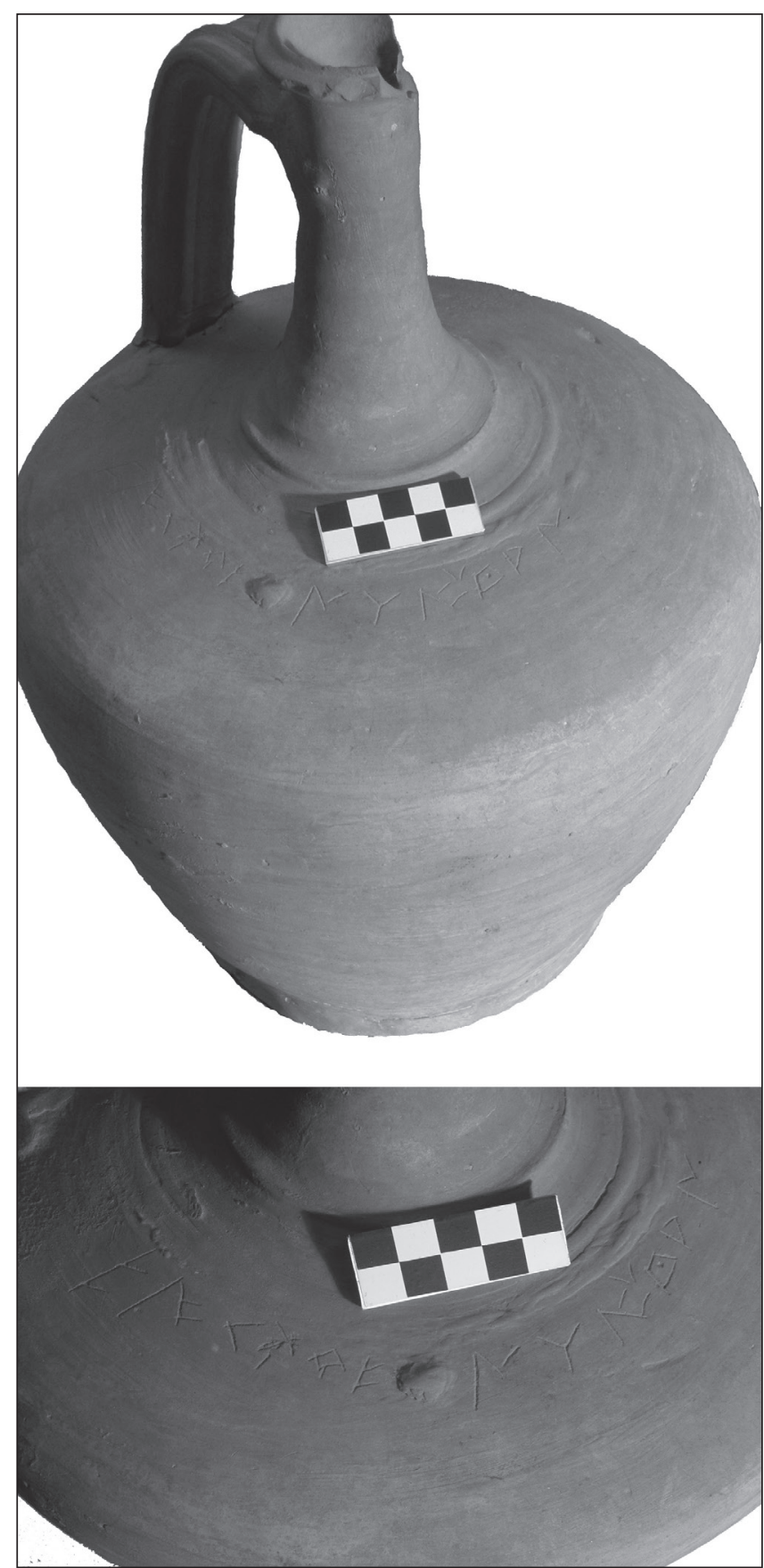

Figura 5. Olpe inscrito: fotografía completa y de detalle de la inscripción (Museo de Teruel).

inicio del texto debería aparecer un nombre personal: eikeboŕ o eiketaŕ, en el que Untermann reconoce un primer elemento eike - posible variante de ikey boŕ o taŕ, ambos documentados como formantes onomásticos (MLH III-1: § 7.59 y 46/115; Rodríguez Ramos 2014: n. ${ }^{\circ}$ 52, 63 y 138).

El último epígrafe que se recoge en MLH es E.5.2 (BDH: TE.05.02), un escueto grafito (il) sobre un plato de cerámica de barniz negro, que Untermann publica sin haber podido estudiar directamente ("Atrián, Brief vom 23.6.59”). ${ }^{39}$ En la ficha que en CAT: 197

39. Es posible que sea al que se refiere Beltrán (1958: 27): "Ortego también realizó hallazgos de cerámica ibérica campaniense: un tiesto con un grafito ibérico que se lee il”, aunque se dedica al yacimiento se señala que "en muchas de estas cerámicas aparecen grafitos (los más frecuentes il y du)", afirmación que también se recoge en el catálogo de En Oliete hace dos mil años: "en algunas cerámicas halladas en «El Palomar» de Oliete (olpe, ánfora) aparecen grafitos (los más frecuentes son IL y DU), al igual que en otros objetos como fusayolas, pondera y algún bloque de piedra" (Vicente et al. 1990: 28, n. ${ }^{\circ}$ 51). Finalmente, Vicente (1982: 263), en una de las memorias publicadas en la revista Teruel, señala el "hallazgo de un numeroso grupo de pondera de cerámica, con variedad de formas y tamaños, aunque casi todos ellos con el grafito ibérico: al”. ${ }^{40}$

El resto de inscripciones proviene de las excavaciones llevadas a cabo por el museo de Teruel en el yacimiento a finales de la década de los setenta y comienzos de la década de los ochenta del siglo pasado. Fueron recogidas en el catálogo de En Oliete hace dos mil años (n. ${ }^{\circ}$ 90, 91, 92 y 93), en fichas muy sucintas, y posteriormente editadas dos veces por L. Silgo (1999; 2001), la primera en la revista Cauce y la segunda en Palaeohispanica..$^{41}$ La primera de estas inscripciones fue recuperada en la casa 4-1 (Vicente et al. 1990: n. ${ }^{\circ}$ 92; Silgo 1999: n. ${ }^{\circ}$ 3, 2001: n. ${ }^{\circ}$ 3; HEp 11, n. ${ }^{\circ}$ 544; BDH: TE.05.08) y está grabada en una pesa realizada con cerámica oxidante, sobre la que se ha aplicado un engobe blanquecino (figura 6). Tiene forma paralelepipédica: la base mide $8,8 \mathrm{y}$ $8,9 \mathrm{~cm}$ y la longitud alcanza $12,6 \mathrm{~cm}$, aunque está incompleta en uno de sus extremos, y está atravesada por un orificio circular. La morfología, efectivamente, es la de una pesa de telar, pero su peso supera el habitual en este tipo de objetos $(1.350 \mathrm{~g})$. El texto está grabado ante cocturam sobre uno de los lados largos, con trazos profundos y unos signos cuya altura alcanza los $2 \mathrm{~cm}$. La lectura es [---]árbiśaren, el primer signo se conserva incompleto, pero puede identificarse como a mejor que como bi. Se pueden aislar en el cierre del texto los sufijos -ar y -en, por norma pospuestos a nombres personales y junto a los que conforman fórmulas para indicar la propiedad del objeto inscrito (MLH III-1: § 512, 521). Por ello es plausible que estén precedidos de un antropónimo. Rodríguez Ramos (2002-2003: 254) ha cuestionado que los sufijos -ar y -en puedan combinarse y estima que serían equivalentes, por lo que solo identifica el segundo de ellos y un nombre personal aŕbi-śar, con dos formantes onomásticos bien documentados (MLH III-1: § 7.13; Rodríguez Ramos 2002-2003: 254; 2014: n. ${ }^{\circ} 11$ y 131; Moncunill 2007: $53)$, por tanto, el texto se conservaría íntegro, a pesar de que el soporte está incompleto.

por la descripción puede entenderse que hace alusión a una pieza recuperada en San Pedro.

40. Sí puede interpretarse como la abreviatura de un nombre personal, pues hay un formante onomástico ibérico, aloŕ/ alos, compatible con dicho inicio (MLH III-1: § 7.9; Rodríguez Ramos 2014: n. ${ }^{\circ}$ 7).

41. También las hemos recogido en una actualización del corpus de inscripciones ibéricas de la provincia de Teruel (Simón e. p.). 


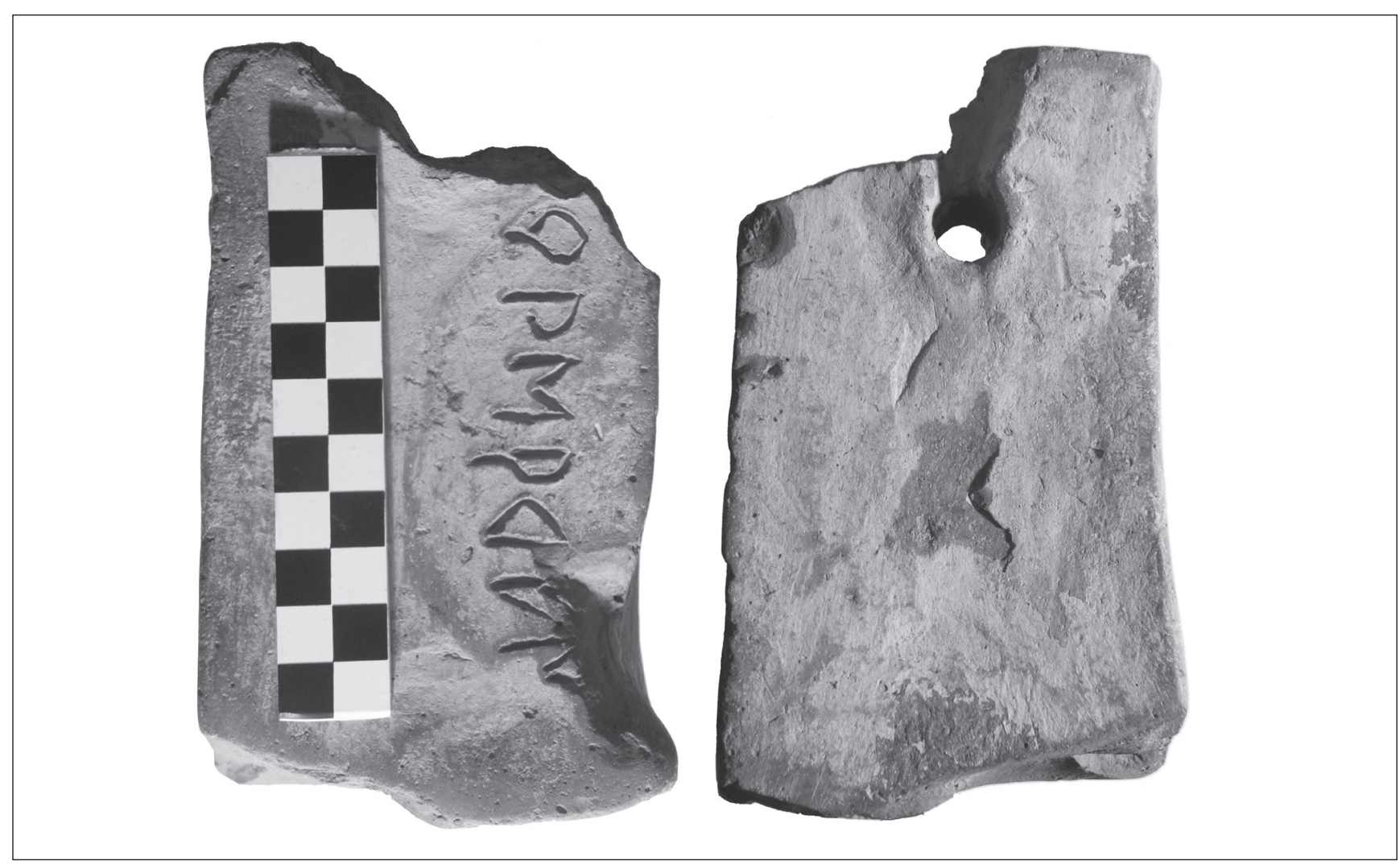

Figura 6. Pesa de telar inscrita (Museo de Teruel).

El segundo texto aparece sobre un ánfora itálica Dressel I A (figura 7) (Vicente et al. 1990: n. ${ }^{\circ} 38$ y 93), ${ }^{42}$ descubierta en la casa 5-2 y sobre la que hay incisos tres esgrafiados post cocturam: a) grabado con trazos muy finos sobre los hombros del ánfora, b) inciso con líneas profundas en el cuello (iŕ) y c) un único signo (ti o to) realizado sobre el pivote. Para el primero hemos propuesto ilturbilosenmí (Simón 2010), que creemos es preferible a otras lecturas como ilduraldisenúi e ilturbiltisenḿi (Vicente et al. 1990; Silgo 1999; 2001; HEp 11, n. ${ }^{\circ}$ 545; DBH: TE.05.09). El epígrafe recoge pues una fórmula de propiedad bien conocida: $\mathrm{NP}$ + en + míi. ${ }^{43}$ El segundo esgrafiado (b) puede leerse como iŕ, aunque sin excluir una lectura iku. ${ }^{44}$ Finalmente, el signo grabado sobre el pivote pudiera ser ti o to, aunque es posible que carezca de valor grafemático y, por tanto, puede clasificarse como una mera marca sin adscripción a una tradición escrituraria concreta. La clasificación del primero y más amplio de los tres esgrafiados como una indicación de propiedad así como la diferente manera en que han sido ejecutados y su disposición, son los argumentos - junto con la naturaleza del recipiente sobre el que aparecen - para clasificar como posibles indicaciones de carácter comercial los dos grafitos

42. En la región se documentan otras inscripciones ibéricas sobre ánforas importadas: E.1.308-351 (Azaila) y E.2.1 (Lécera).

43. MLH III-1: § 521 y 534. El nombre está compuesto de los formantes iltur y bilos, MLH III-1: $§ 7.62$ y 39; Rodríguez Ramos 2014: n. ${ }^{\circ} 45$ y 66.

44. No obstante, el alógrafo ku3 es muy poco común (MLH III-1: 253), mientras que ŕ1 es característico de época iberorromana (Rodríguez Ramos 2004: 130).

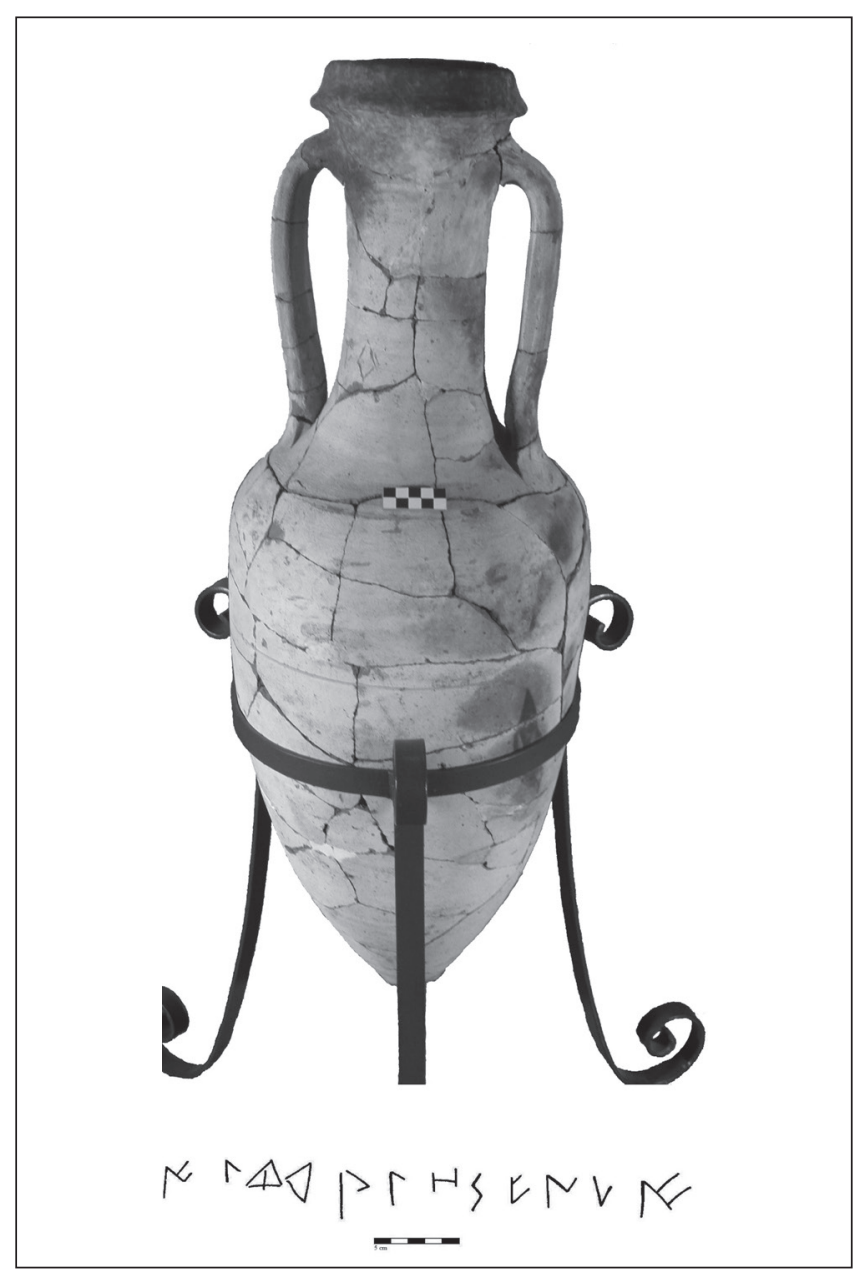

Figura 7. Ánfora inscrita de El Palomar: fotografía y dibujo del grafito a (Museo de Teruel). 
más breves. Por las mismas razones que se han expuesto al comentar el epígrafe grabado sobre la pesa de telar, es imposible que, como defiende Silgo (1999: 28; 2001: 348) (HEp 11, n. ${ }^{\circ}$ 545; Moncunill 2007: 186), esta inscripción pueda identificarse con ninguna de las trasmitidas por Fidel Fita (E.5.3-4).

Los dos últimos esgrafiados están realizados sobre sendas fusayolas, ambos hechos ante cocturam (BDH: TE.05.06, figura 8). ${ }^{45}$ La primera proviene de la casa $7-4$, tiene forma troncocónica y está fabricada con cerámica oxidante; su altura es de $2,4 \mathrm{~cm}$ y el diámetro máximo de $3,4 \mathrm{~cm}$, con un orificio que la atraviesa de 1,2 cm de diámetro. El texto está grabado en la cara superior de la pieza, en torno al orificio central, con signos cuya altura alcanza los seis milímetros. La lectura tiene varios puntos conflictivos, que afectan al segundo y último signos. Este segundo se reduce a un pequeño triángulo dispuesto en la parte superior de la caja de escritura, que se ha interpretado como un "adorno" para marcar el final del texto (Silgo 1999: 27) y como un insólito o mal ejecutado alógrafo de r (Beltrán 1996: 143; Rodríguez Ramos 2001: 284; 2002: 272; Moncunill 2007: 228; Ferrer 2008: 260). El tercer signo es igualmente peculiar, pues se asemeja a una $i$ latina. Pudiera ser un alógrafo de ba, pero este silabograma aparece también en el texto con su forma característica (sexto signo). Otras propuestas son que se trate de una interpunción (Silgo 1999: 27), que deba relacionarse con un peculiar signo solo atestiguado en el plomo de Palamós (C.4.1) y en uno de los grafitos rupestres de la Cerdaña (Silgo 1999: nota 3, 2001: 347; Rodríguez Ramos 2001: 283-284) o que sea un alógrafo de $\mathrm{T}$, un signo cuyo valor se ha discutido pero que, con toda probabilidad, es m (Ferrer et al. 2011: 25-26; Ferrer 2014: 246-248. Cf. M. Sanz 2014). El segundo tampoco está exento de polémica, pues se ha leído como tu o ka, aunque la secuencia kuka apenas encuentra paralelos, incluso pudiera ser $\mathbf{u}$, algo que parece improbable ya que supondría la redundancia de la vocal. ${ }^{46}$

Los problemas reseñados explican las divergencias entre los editores de este complejo texto: kutubanubarbiane (Vicente et al. 1990: n. ${ }^{\circ}$ 70), kutubanḿbarbianer (Beltrán 1996: 143), kutuInḿbaŕbiane+ (Silgo 1999: n. ${ }^{\circ}$ 1, 2001: n. ${ }^{\circ}$ 1), kutu / nḿbarbiane (Fragmentos de Historia, p. 320), kutu? nḿbaŕbianer (Ferrer 2008: 260) y kutu+nóbaŕbiane+ (Simón e. p.). El inicio kutu lo comparte con otra fusayola inscrita recuperada en Cabrera de Mar: kutukiŕbitatikoukebosekoTḿ (Ferrer et al. 2011), texto que Ferrer (2014) identifica como un signario no dual. Este autor ha identificado varios signarios de este tipo, uno en la citada pieza de Cabrera de Mar y otro en una inscripción rupestre de Osona. Su interpretación para la fusayola olietana es que también recoge un signario, aunque simplificado, pues comparte con los anteriores el inicio kutu y está

45. Sobre este tipo de objetos, véase Castro (1980).

46. Ballester y Turiel (2007: 40) no descartan la opción de leer el inicio de este texto como kuu-, que comparan con una posible lectura para una fusayola inscrita de la colección Turiel. La homografía entre los signos u y tu en fechas tardías, como parece suceder en este epígrafe, ha sido puesta de relieve por Rodríguez Ramos (2005: 25). seguido de los tres grafemas para las nasales, que en otros signarios aparecen al final, estando elididos los caracteres intermedios: kutumnḿ baŕbianer (Ferrer 2014: 237-238).

La segunda fusayola inscrita apareció en la calle I (BDH: TE.05.07). También está realizada con cerámica oxidante y tiene forma bitroncocónica, cuya altura alcanza $2,3 \mathrm{~cm}$ y el diámetro $4,4 \mathrm{~cm}$; el orificio que la atraviesa mide $1,2 \mathrm{~cm}$ de diámetro. El texto está grabado en la cara superior y la altura de los grafemas oscila entre 6 y 9 milímetros. La lectura es compleja y se refleja en las discrepancias entre los editores: sanisaausurka (Vicente et al. 1990: n. ${ }^{\circ}$ 91), śanbaśaruśtírn (Silgo 1999: n. ${ }^{\circ}$ 1), śanbaśarusúúrn (Silgo 2001: n. ${ }^{\circ}$ 1), ośanbaśaruśtiŕ (Ferrer 2008: 259) y śaniśaauśtíro (Simón e. p.). Además, se emplea la scriptio continua y no es sencillo determinar si hay que segmentar o no el texto y, en tal caso, en qué punto concreto. Ferrer (2008) interpreta el epígrafe como un NP (ośanbaś) seguido del sufijo -ar y de uśtir, que compara con iunstir/iuśtir, término ibérico ampliamente documentado (véase Moncunill 2007: 198-199, con la bibliografía anterior). Pero el punto que señala como inicio del epígrafe (ośanbaśaruśtió) es cuestionable, especialmente si aceptamos la posibilidad de identificar un nombre personal śaniśar, como sostiene Untermann (2001: nota 10), quien estima que el séptimo grafema no es a sino una r levógira. El antropónimo, como indica Moncunill (2007: 276), estaría compuesto por los formantes śani ( $M L H$ III1: § 7.99) y śar (Rodríguez Ramos 2002-2003: 254, 2014: n. ${ }^{\circ}$ 131; Moncunill 2007: 53).

Estos objetos se emplean en el hilado y se asocian con la mujer, no solo por los paralelos que al respecto ofrecen las culturas clásicas sino también porque en la iconografía ibérica siempre son féminas las que aparecen tejiendo o hilando. Los ejemplos son un pequeño relieve en piedra de La Albufereta (Alicante), en el que se representa a una mujer con rueca y huso (Llobregat 1972: 150-151, lám. 7), una tinaja que parece proceder de San Miguel de Liria, en la que han pintado dos mujeres que sostienen instrumentos de hilado junto a un telar (Izquierdo y Pérez Ballester 2005: 85-103), un fragmento de terracota de Coimbra del Barranco Ancho, con una mujer con huso, y, finalmente, una cerámica de La Serreta, en la que aparece un objeto identificado como un telar y ante el que hay un personaje que parece una mujer con un huso (Maestro 1989: 259-261). ${ }^{47}$

La mayoría de grafitos documentados sobre este tipo de instrumentos son muy breves, de los que el conjunto más numeroso proviene de Azaila (E.1.438452, Beltrán 1976: 248-252, figuras 66-68; 1995: 55-56; 2013), pero también hay un grupo de textos largos, que no son comunes sobre este tipo de objetos en

47. Sobre todas estas representaciones, uid. también Izquierdo (2001: 299-309). La asociación entre las mujeres y el trabajo textil también es común en la cultura romana, un ejemplo muy interesante lo ofrece una inscripción grabada sobre una pesa de telar de Caesaraugusta: telas multas texat, uirum bonum inueniat. Ama lateres! Facimus fausta fel[icia], es decir: "Que teja muchas telas y (te) encuentre un buen marido. ¡Aficiónate a las pesas de telar!: hacemos cosas propicias y felices", según lectura y traducción de Beltrán y Beltrán (2012). 


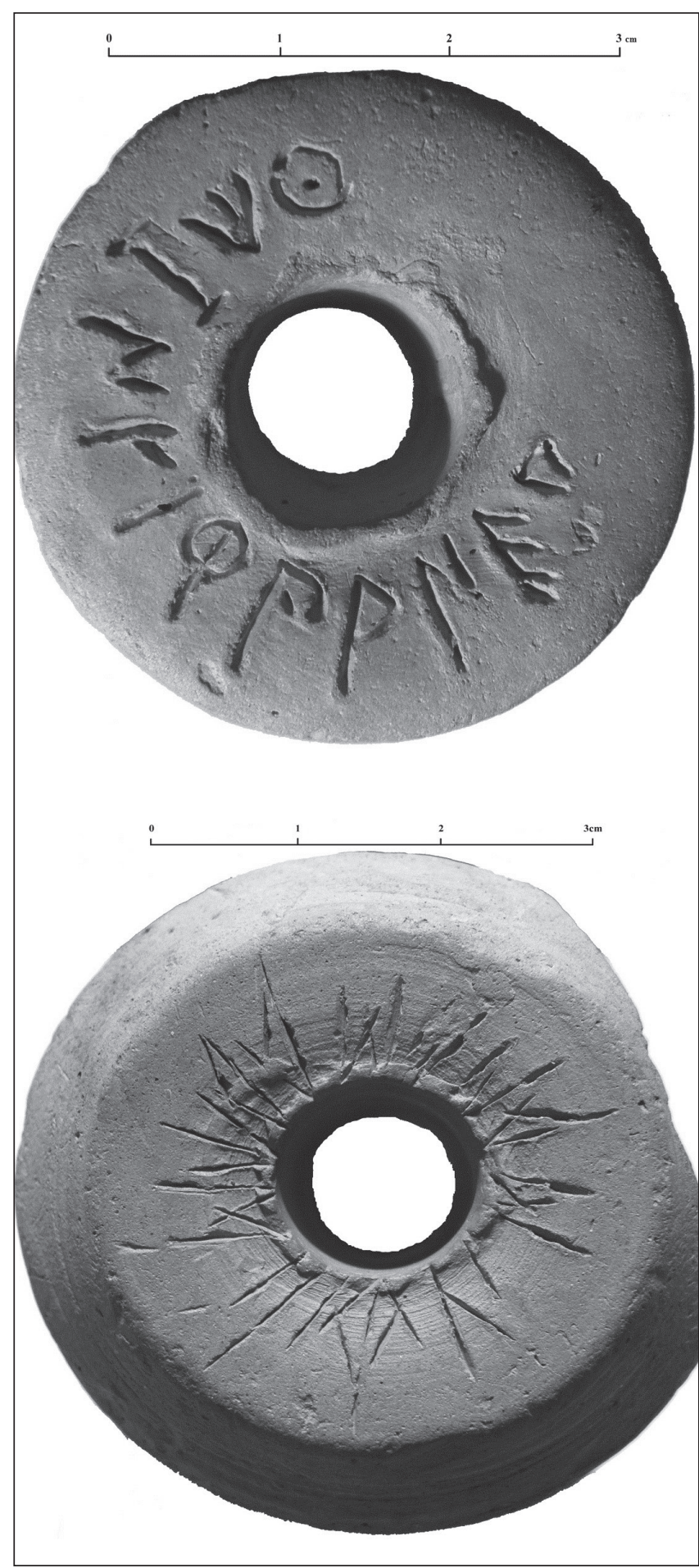

Figura 8. Fusayolas inscritas de El Palomar (Museo de Teruel).

otras culturas mediterráneas y que, por tanto, parecen propios del ámbito paleohispánico: ibérico y, en menor medida, celtibérico. ${ }^{48}$ Uno de los rasgos más sobresalientes es que, como sucede en las torteras de El Palomar, los textos amplios están en su mayoría grabados con anterioridad a la cocción. En ellos hay nombres personales y también un término recurrente, kaśtaun/kastaum, que comparece en tres casos

48. Véanse los trabajos de conjunto de Ferrer (2008) y Beltrán et al. (e. p.).
(Sant Julià, Soses, Vilademuls y quizá la del Vilar, si keśtan es una variante del citado término) (Ferrer y Sànchez 2017: figura 5), que se ha propuesto sea un apelativo femenino, equivalente a muchacha o similar (Ferrer 2008: 265-266), a partir de los paralelos que ofrecen las fusayolas de época imperial de Autun (Galia), con textos amatorios latinos y galos (Lambert 2002: 317-337), o bien que haga referencia al propio objeto, es decir, que sería la palabra ibérica para fusayola (Rodríguez Ramos 2005-2006: 469-471; Ferrer y Sànchez 2017: 226).

\section{Cultura escrita en El Palomar}

Literacy es un término anglosajón que no tiene un equivalente exacto en castellano, pues "alfabetización" o "alfabetismo" tienen un significado más restringido. Pudiera traducirse por "cultura escrita", aunque en los estudios sobre el mundo clásico es común el uso de la palabra original desde la influyente obra de W. V. Harris Ancient Literacy (1989). ${ }^{49}$ Las inscripciones sobre el instrumentum son fundamentales para estudiar esta cuestión y más aún cuando el objetivo son sociedades antiguas que, como la ibérica, carecen de una tradición manuscrita y los únicos textos que se preservan son epígrafes. De hecho, en muchas ocasiones son los únicos testimonios disponibles para determinar la difusión, tanto geográfica como social, de la escritura. ${ }^{50}$ Los esgrafiados sobre el instrumentum atestiguan el uso cotidiano y privado de la escritura en ambientes domésticos, aunque también, como veremos, los epígrafes sellados y grabados antes de la cocción de las cerámicas informan sobre los productores de estos objetos.

Es difícil de determinar el grado de alfabetización de quienes realizaron los esgrafiados (Véase Prosdocimi 1990: 194). Solo los ejemplares más amplios, aquellos compuestos por varias palabras, permiten aseverar la alfabetización de quien los escribió. En el caso de los más breves, como los grafitos monolíteros, la cuestión es muy discutible pues, aunque morfológicamente coincidan con signos del semisilabario, pueden carecer de valor grafemático y pudieron haberse empleado como simples marcas. ${ }^{51}$ Pero aún negando esta última posibilidad, este tipo de esgrafiados no son argumento suficiente para considerar letrado a su ejecutor, aunque sí es sintomático, especialmente cuando los testimonios de este tipo se acumulan en un mismo lugar, de que sus autores tenían, al menos, una familiaridad con la escritura. Es decir

49. Para el concepto Woolf (2000); sobre este tipo de estudios, uid. Werner (2009).

50. Un estudio sobre este tipo de testimonios y su valor para conocer la difusión de la escritura en Evans (1987). Un intento sistemático de evaluar la literacy a partir de la epigrafía lo representa la monografía de Raybould (1999) sobre Britannia, a partir del RIB, uno de los pocos corpora epigráficos en los que se ha catalogado de forma sistemática el instrumentum inscriptum, que en el caso de esta provincia, además, cuenta con conjuntos especialmente relevantes como las tabellae defixiones y las tablillas de madera de Vindolanda. Es igualmente destacable el proyecto sobre la cultura escrita de Augusta Raurica.

51. Sobre la interpretación de este tipo de testimonios: Simón (2013: 560-562). 
que, aunque el individuo que realizó el grafito no sea letrado, sí tiene una idea de qué es la escritura y conoce su repertorio de signos. Este aspecto debe subrayarse, ya que es durante los siglos II y i a. C. cuando la escritura aparece por primera vez en esta región. Asimismo, hay que reseñar como estos testimonios más breves se documentan en yacimientos en los que también se han recuperado epígrafes propiamente dichos, lo que permite contemplarlos como un fenómeno paralelo a la difusión del signario paleohispánico (Simón 2013: 561-562).

El problema señalado, en torno a la información que proporcionan los esgrafiados sobre el grado de alfabetismo de sus autores, también afecta a otros grafitos igualmente breves, aunque más amplios que los monolíteros. Incluso cuando registran nombres propios completos hay que tener en cuenta que determinadas personas pudieron aprender a escribir exclusivamente su nombre y que, por tanto, su nivel de alfabetización era mínimo. ${ }^{52}$ En definitiva, los esgrafiados son una fuente inestimable para poder aproximarse a la difusión y uso de la escritura, pero la información que ofrecen sobre el grado de alfabetización de sus autores es, por desgracia, limitada.

En El Palomar solo se documentan inscripciones sobre instrumenta, pues aunque se han recuperado dos fragmentos de estelas decorados con lanzas, por lo que pueden incluirse en el conjunto de estelas del Bajo Aragón - del que serían los testimonios más occidentales-, no hay sobre ellas resto alguno de inscripción, algo que encaja bien con lo que sucede en este grupo de monumentos, en el que son excepcionales los ejemplares inscritos (Vicente et al. 1990: n. ${ }^{\circ}$ 138-139). Untermann recogía cinco textos de Oliete en MLH (E.5 = BDH: TE.05), uno de ellos un sello (E.5.5 = BDH: TE.05.05) y dos que, quizá, pudieran provenir de San Pedro (E.5.3-4 = $B D H$ : TE.05.03-04). Posteriormente, se han publicado cuatro más, recogidos en el catálogo de En Oliete hace dos mil años y editados por L. Silgo (1999; 2001), además de las noticias del hallazgo de otros grafitos breves, entre los que no solo hay monolíteros sino también bilíteros: como el recogido por Juan Cabré (1911: figura 134), bato; varios ejemplos de il (E.5.2 = BDH: TE.05.02; CAT: 197); el grafito le sobre un jarrito (Vicente et al. 1990: $\mathrm{n} .^{\circ}$ 64); y al en varias pesas de telar (Vicente 1982: 263). Cuantitativamente no es fácil de valorar, pero lo cierto es que si hay yacimientos ibéricos que cuentan con centenares de grafitos, como Ensérune (B.1 = $B D H$ : HER.02) y Azaila (E.1 = BDH: TE.02), en el resto la cantidad es mucho más discreta y apenas se pueden enumerar quince que superen la decena, ${ }^{53}$ mientras que entre cinco y diez

52. Youtie $(1971 ; 1975)$ ha estudiado, a partir de la documentación papirológica de Egipto, la existencia de individuos

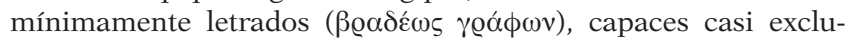
sivamente de escribir su nombre, y también la delegación de la escritura por parte de los analfabetos.

53. Pech Maho (B.7 = BDH: AUD.05), Ruscino $(\mathrm{B} .8=B D H$ : PYO.01), Elne (B.9 = BDH: PYO.02), Ampurias (C.1 = BDH: GI.10), Ullastret (C.2 = BDH: Gi.15), Pontós (C.3 = BDH: GI.08), Burriac $($ C.7 = BDH: B.44), Badalona $($ B.8 = BDH: B.41), Rubí (C.11 = BDH: B.17), Ca n'Oliver (Cerdanyola del Vallès, C.12 $=B D H:$ B.20), Sant Miquel de Sorba (D.4 = BDH: B.01), Can encontramos catorce. ${ }^{54}$ La mayoría de ellos, además, son yacimientos de rango politano: Ampurias (C.1 = $B D H$ : GI.10), Ullastret (C.2 = BDH: GI.15), Burriac $(\mathrm{C} .7=B D H:$ B.44), Badalona $(\mathrm{C} .8=B D H:$ B.41 $)$, Tarragona $(\mathrm{C} .18=B D H$ : T.11) o Liria $(\mathrm{F} .13=B D H$ : V.06), parte de los cuales reúnen los corpora locales más importantes de la epigrafía ibérica.

En El Palomar se documentan diferentes tipos de inscripciones sobre instrumenta, realizadas sobre objetos igualmente diversos: pesas de telar, fusayolas y recipientes de diferente tipo (ánfora, jarra, etc.), aunque todos ellos fabricados en cerámica, que es el material sobre el que aparece la mayor parte del conjunto de inscripciones que conforman el corpus ibérico, algo que se explica tanto por su importancia en el mundo antiguo como por su perdurabilidad. Las técnicas documentadas en el yacimiento son el esgrafiado, antes y después de la cocción, y el estampillado. Incluyen textos largos y grafitos brevísimos, de dos o un único signo, que son frecuentes y predominan en los conjuntos cerámicos de la región, como sucede en Azaila (E.1 = BDH: TE.02). Sin embargo, El Palomar incluye varios textos de los que podemos denominar largos, es decir, aquellos que incluyen un nombre personal completo y alguno de los sufijos de propiedad ibéricos (-en, -ar o -mí), que no son característicos de este periodo (Simón 2013), en el que predominan los grafitos escuetos como en Azaila. En uno de los textos perdidos y transmitidos por Fidel Fita se puede reconocer, como sugiere Untermann, un antropónimo ibérico (arbiśkaŕ), que comparte su primer formante con el nombre grabado sobre la pesa de telar y que está seguido del morfo -en: aŕbiśaren. En otros tres epígrafes es posible identificar la fórmula de propiedad compuesta por un nombre personal y los sufijos -en y -ḿi: ilturbilosenḿi, binkiśauŕenḿn[i] y eiketaŕenmíekuan, este último seguido de un término, ekuan o kuan, que presumiblemente hace referencia a la jarra sobre la que está grabado este texto.

También se documentan epígrafes más breves: signos aislados o grafitos bilíteros como il, que, como ya se ha señalado, se documenta sobre diferentes objetos recuperados en este yacimiento. Elusiva es la interpretación de estos grafitos más escuetos, pero es plausible que, al menos, una parte de ellos sean abreviaturas. En el caso de il son varios los formantes onomásticos ibéricos que comparten dicho inicio: iltiŕ, iltun o iltur (MLH III-1: § 7.61 y 62; Rodríguez Ramos 2014: n. ${ }^{\circ}$ 65-66), el último de los cuales encabeza uno de los antropónimos documentados en el yacimiento: ilturbilos. En el ánfora propiedad de

Sotaterra (Solsona, D.5 = BDH: L.03), Guissona, Campello (G.9 $=B D H:$ A.08) y Alarcos (BDH: CR.01).

54. Montlaurés (B.4 = BDH: AUD.02), Sant Julià de Ramis (BDH: GI.13), Torre dels Encantats (Arenys de Mar, C.6 = BDH: B.47), Camí Vell del Llor (Sant Boi de Llobregat, $B D H$ : B.36), Els Prats de Rei (Sigarra, $B D H$ : B.12), El Turó del Vent (Llinars del Vallès, C. $25=B D H$ : B.29), Can Rossó $($ Argençola $=B D H$ : B.09), Sant Miquel (Vinebre, C.26 = BDH: T.06), Lérida ( $B D H$ : L.8), Tarragona ( $B D H$ : T.11), La Balaguera ( $B D H$ : CS.13), Liria $(\mathrm{F} .13=B D H:$ V.06), Valencia $(B D H:$ V.12) y La Cabañeta $(\mathrm{El}$ Burgo de Ebro, $B D H$ : Z.11). Esta serie de cuantificaciones fue realizada para elaborar los mapas del trabajo Beltrán et al. e. p. 

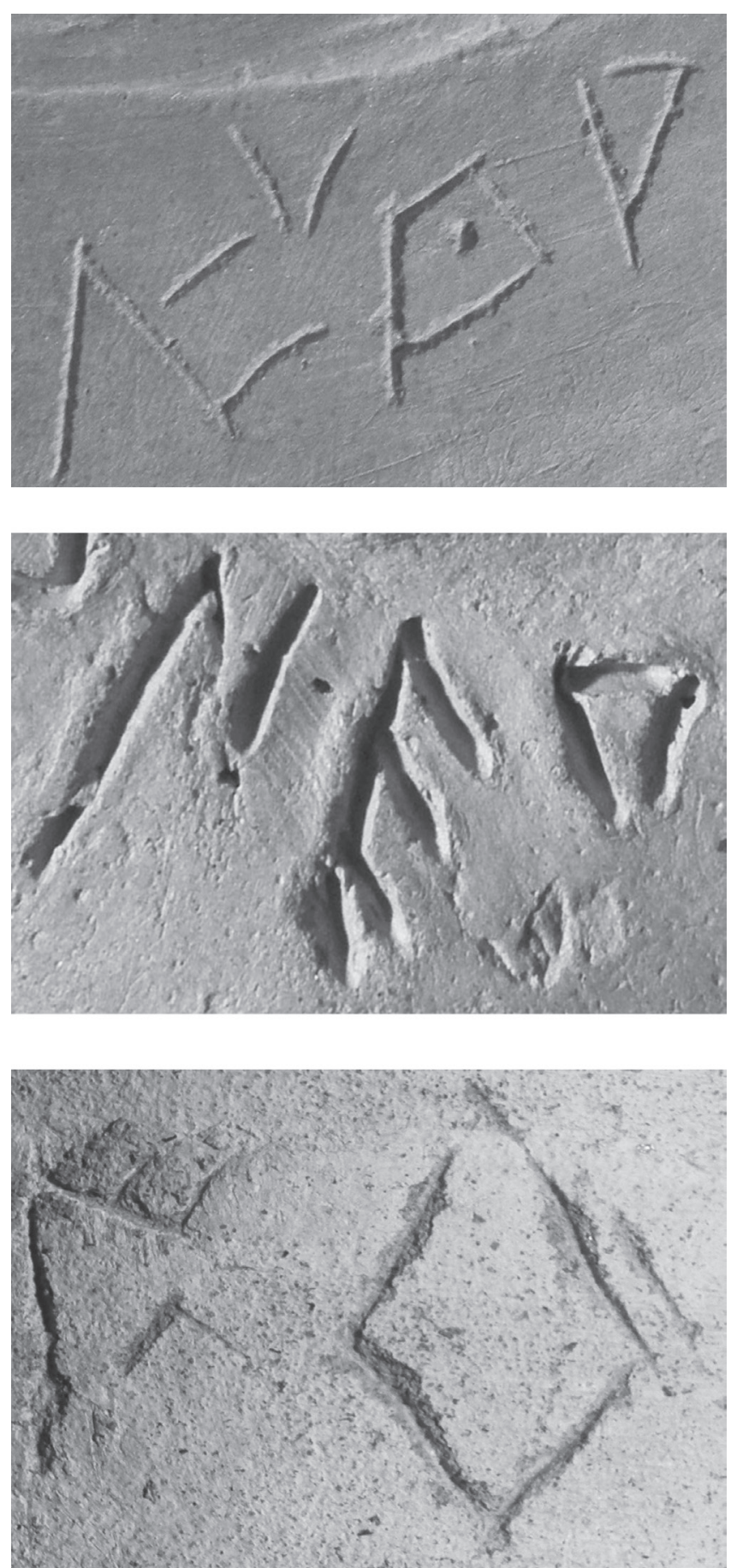

Figura 9. Detalle de varias inscripciones: 1. Grafito sobre el olpe; 2. Grafito sobre fusayola; y 3. Grafito b sobre el ánfora.

ilturbilos (ilturbilosenmii), además de esta inscripción, hay dos epígrafes más: uno bilítero grabado sobre el cuello y un segundo reducido a único signo en el pivote. Es posible, a juzgar por su ubicación así como no poderse interpretar como abreviaturas del nombre del propietario y por el tipo de objeto en el que aparecen, un ánfora de procedencia itálica, que su función sea la de indicaciones de carácter comercial. Es interesante señalar que entre los dos caracteres que conforman el epígrafe realizado en el cuello hay un signo con forma de ángulo en la parte central de la caja de escritura, cuyo valor, si es que lo tiene, es desconocido (¿quizá una interpunción?), pero que puede cotejarse con otros signos de interpretación igualmente dudosa y que se ubican en la parte superior de la caja de escritura en otras dos inscripciones de este yacimiento: el esgrafiado sobre la jarra y uno de los grabados sobre una de las fusayolas (figura 9).

No solo se documentan inscripciones de propiedad en el corpus olietano, sino que también hay epígrafes realizados antes de la cocción de las cerámicas y que, por tanto, nos informan sobre el uso de la escritura por parte de los productores. Un ejemplo de ello es el sello impreso sobre una de las pesa de telar, un tipo de marcas bien conocido en el valle medio del Ebro sobre diferentes objetos cerámicos: mortaria, tinajas y las propias pesas de telar. Sobre estas últimas se atestiguan sellos en Azaila, Lécera, Durón de Belmonte, Alcañiz, Bilbilis y Foz Calanda (Simón 2013: EP), de alguno de los cuales se conocen varias improntas, aunque la que proviene del Palomar es un ejemplar único. Las estampillas sobre este tipo de objetos son casi exclusivas del valle del Ebro y varias de ellas se han recuperado en los hornos alfareros de Mas de Moreno (Foz Calanda) (Gorgues 2009, BDH: TE.09). Es una peculiaridad de estos sellos la brevedad de sus epígrafes que, como sucede en el ejemplar de Oliete, 'um', se reducen en ocasiones a dos signos unidos en nexo, como si fuesen un monograma, así sucede también en las pesas de telar de Tiro de Cañón (Alcañiz), 'iš', y Durón de Belmonte, 'un' (E.14.4, Simón 2013: EP5 y EP10).

Son esgrafiados los otros tres textos grabados antes de la cocción: uno aparece sobre una pieza que tiene forma de pesa de telar y los otros dos en sendas fusayolas. Son comunes los epígrafes sobre el instrumental relacionado con el trabajo textil en los yacimientos del valle medio del Ebro durante el Ibérico final: sobre pesas de telar se atestiguan, además de los sellos inscritos ya mencionados, esgrafiados (Simón 2012b), improntas de anillos ${ }^{55}$ y todo tipo de marcas; ${ }^{56} \mathrm{y}$, por su parte, en las fusayolas se atestiguan, además de las decoraciones propias en este tipo de objetos, marcas, grafitos breves - de uno, dos o tres signos- y textos más amplios.

Los dos textos largos que aparecen sobre las fusayolas están realizados antes de la cocción y, por tanto, fueron inscritos en el momento de su fabricación, antes de su cochura. Esto supone que la inscripción era parte del objeto desde su concepción y surge la pregunta de si trata de una producción doméstica, es decir, que el propietario o propietaria realizó la pieza y grabó también el epígrafe o si, por el contrario, fue realizada por un alfarero, al que se solicitó que incidiese el texto. ${ }^{57}$ Esto último supondría que serían objetos de encargo, del mismo modo que se ha propuesto para la cerámica ibérica con decoración pintada

55. Un buen ejemplo proviene del propio Palomar, las improntas de una gema engastada sobre tres pesas de telar, en la que se representa una escena de la comedia griega: un esclavo sentado sobre un altar (Vicente et al. 1990: n. ${ }^{\circ}$ 31; Simón 2016).

56. Véanse los ejemplos de El Palomar: Vicente et al. (1990: n. $\left.{ }^{\circ} 30,32-35\right)$.

57. Alfaro (1997: 209) estima, en el caso de las pesas de telar, que serían una producción doméstica. 


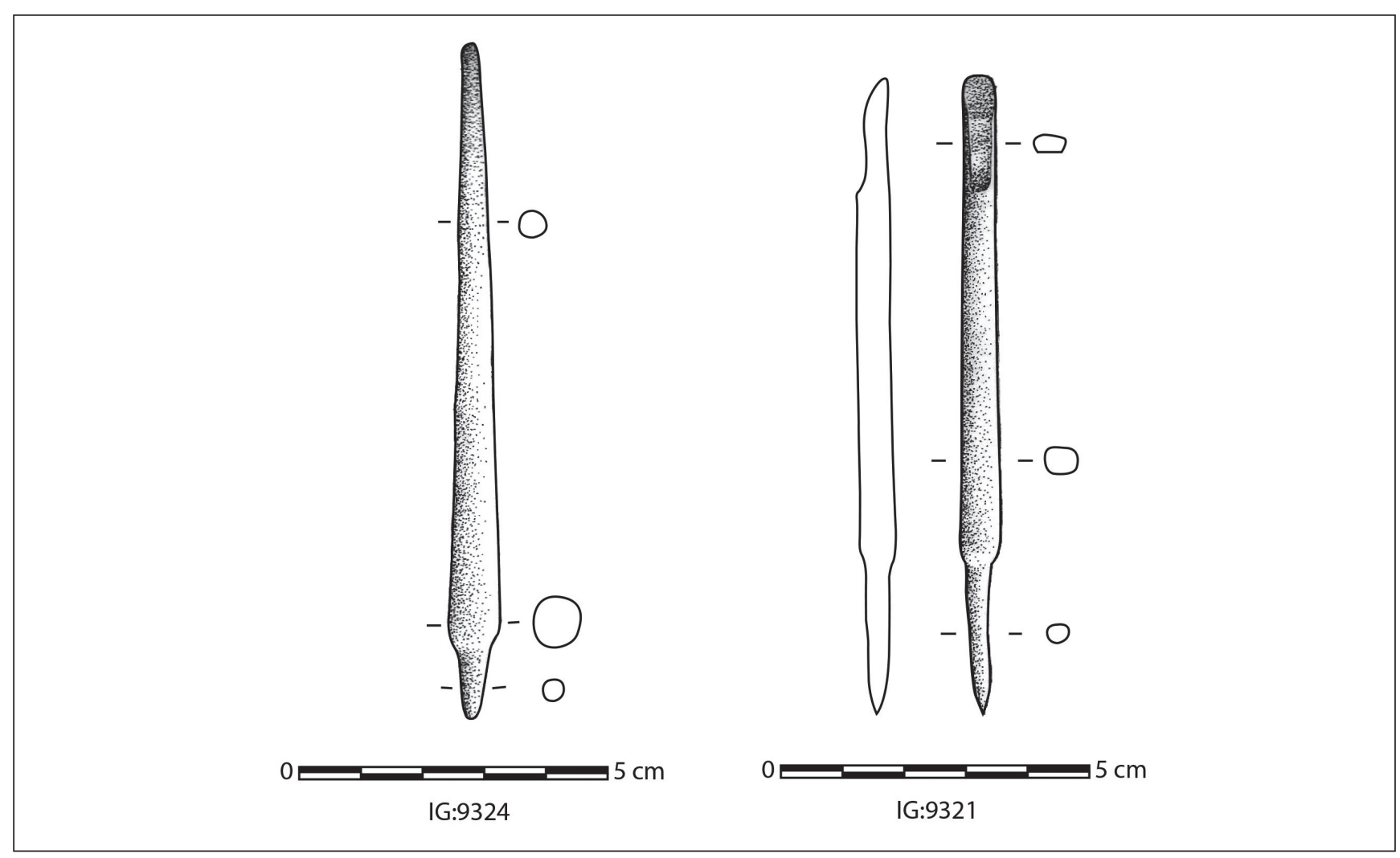

Figura 10. Estilos de hueso de El Palomar.

figurada y que, en casos como Liria o el Castelillo, está igualmente inscrita (Aranegui 1997: 161-175). ${ }^{58}$

Por último, hay que reseñar la información que ofrecen los instrumentos de escritura, en este caso dos estilos de hueso recuperados en el yacimiento (figura 10). ${ }^{59}$ Este tipo de objetos apenas se ha valorado a la hora de estudiar la literacy en la antigüedad, aunque son fundamentales, pues testimonian el uso de soportes perecederos de escritura, en este caso de tablillas enceradas. En el valle medio del Ebro proceden de yacimientos de rango politano: Azaila, Zaragoza (Salduie), Botorrita (Contrebia Belaisca) y La Cabañeta del Burgo de Ebro, la única excepción es El Palomar. La escasa atención prestada a la industria ósea de la segunda edad del Hierro hace plausible que hayan pasado desapercibidas otras piezas de este género, pero con los datos disponibles actualmente la impresión es que en la depresión central del Ebro aparecen en el Ibérico final —quizá como innovación aportada por los romanos- y de forma coetánea a las inscripciones ibéricas y celtibéricas, habiéndose hallado en ciudades que también cuentan con algunos de los corpora epigráficos más notables, como son Azaila y Botorrita (Simón e. p. a.).

58. Olmos (1987). En la CAT: n. ${ }^{\circ} 410$, se indica que en El Cabezo de San Pedro aparecieron indicios de la existencia de un alfar: "pellas de barro informes con huellas digitales y fragmentos de cerámica pasados de horno y vitrificados".

59. Catálogo Oliete n. ${ }^{\circ}$ 95-96; Catálogo Fragmentos, 321; Vicente (2007: 188); Blasco (2018).
El conjunto de inscripciones de El Palomar, la relativa extensión de una parte — frente a los brevísimos grafitos que dominan el registro epigráfico del periodo y la región- y el hallazgo de varios estilos de hueso son significativos sobre la cultura escrita de los habitantes de este pequeño emplazamiento de carácter rural. ${ }^{60}$ Muy interesante es la posibilidad, señalada por Ferrer (2014), de que una de las inscripciones sobre fusayola contenga un signario abreviado. ${ }^{61}$ Todo ello contrasta con la concentración de la epigrafía en las ciudades, pero también con lo que sucede en otros yacimientos de análogo tamaño y rango a El Palomar. En el próximo yacimiento de Los Castellares (Herrera de los Navarros) no se conoce ninguna inscripción, salvo algunos signos aislados sobre fusayolas. ${ }^{62} \mathrm{Su}$ organización es la típica

60. Burillo (2009: 179) señala que "existen dos tipos de asentamiento muy diferenciados por su tamaño, los que no alcanzan a hectárea de extensión, que identificamos como poblados, asentamientos rurales o castros, dado que la mayor parte de ellos se encuentran en altura y con elementos defensivos, muralla y foso". El Palomar entra dentro de esta categoría de establecimiento rural, a los que los autores clásicos se refieren como castella, uici y pirgoi, véase Rodríguez Blanco (1977).

61. Sobre este tipo de inscripciones, véase también Velaza (2012a). Otro ejemplo parece atestiguarse sobre una tinaja recuperada en un pequeño establecimiento rural: Val de Alegre I (Díaz y Mayayo 2008: 199-200; Ferrer 2014: 236-237).

62. De Sus (1986). Velaza (1991: 85) recoge un grafito: kail, grabado sobre un ánfora greco-itálica, del que no hemos encontrado más información. 
de los llamados poblados de calle central, limitada por la muralla que conforman las paredes traseras de las casas. Se ubica en la cima de un pequeño promontorio y tiene unas dimensiones de 100 metros de largo por 22 de ancho, que ocupan una veintena de casas, de las que solo se han excavado dos. De la casa 2 procede el conjunto de fusayolas ya mencionado, algunas de las cuales presentan marcas que solo en algún caso pudieran tener valor grafemático, pero ninguna inscripción propiamente dicha; el yacimiento es, en parte, coetáneo a El Palomar, aunque se destruye antes: en la primera mitad del siglo II a. C. ${ }^{63}$ Por su parte, Torre Cremada en Val del Tormo, en el valle del Matarraña (BDH: TE.13), es un poblado de dimensiones igualmente reducidas, pues se limita a una única hectárea y, en parte, también es coetáneo al Palomar, pues fue fundado en torno al año 100 a. C. y abandonado a finales de dicha centuria. Se ha excavado parte de una fortificación que parece funcionar a modo de ciudadela, donde solo se han recuperado cuatro cerámicas con brevísimos grafitos: ben (sobre un pie de campaniense A tardía), e (sobre una copa de cerámica ibérica), bas o IS (sobre copa de cerámica pintada) y A (en un vaso de sigillata itálica). ${ }^{64}$ Estos paralelos refuerzan la excepcionalidad de El Palomar, para la que no tenemos una explicación satisfactoria aunque sí creemos que existe tanto por el número de grafitos recuperados, si se tiene en cuenta la cantidad que de ellos hay en otros corpora locales, como por su naturaleza, pues entre ellos se cuentan varios ejemplares con fórmulas de propiedad completas y una pareja de textos largos sobre fusayolas -en un periodo en el que predominan los grafitos más breves-, además de haberse recuperado dos stili de hueso, que aseguran el uso de tablillas enceradas. ${ }^{65}$ Un yacimiento que por su tamaño debió ser un establecimiento secundario, como un vicus o un pagus, en el territorium de una de las ciudades del entorno, aunque no es posible determinar cuál de ellas. La comparación con otros yacimientos de rango secundario, como Los Castellares y Torre Cremada, acentúa también la percepción del Palomar como un yacimiento con una práctica escrita superior a lo que se observa en otros poblados ibéricos.

Ignacio Simón Cornago Investigador del Programa Marie Sklodowska-Curie (grant agreement, n. ${ }^{\circ}$ 794476) Università degli Studi di Roma Tor Vergata isimoncornago@gmail.com

Rebut: 4-5-2018

Acceptat: 22-5-2018
63. Burillo (2007a: 182-185), Burillo et al (2008: 15-16) lo relacionan con la campaña de Nobilior (año 153).

64. Gorgues et al. (2003), sobre el yacimiento: Moret et al. (2006: 81-131).
65. El Castelillo está próximo, pero no parece pervivir más allá de mediados del siglo II a. C. CAT: n. ${ }^{\circ}$ 146, sobre este yacimiento véase también: Loscos et al. (2007). 
Aguarod, C. (2017). Cerámica común de mesa y de cocina en el valle del Ebro y producciones periféricas. En: Fernández, C., Morillo, A., Zarzalejos, M. (eds.). Manual de cerámica romana III. Cerámicas romanas de época altoimperial III: cerámica común de mesa, cocina y almacenaje. Imitaciones hispanas de series romanas. Otras producciones. Museo Arqueológico Regional (Cursos de Formación Permanente para Arqueólogos 4). Madrid: 15-95.

Alfaro, C. (1997). Mujer ibérica y vida cotidiana. En: La Dama de Elche, más allá del enigma. Dirección General de Patrimonio Artístico (Debates sobre patrimonio artístico 1). Valencia: 193-218.

Alfayé, S. (2009). Santuarios y rituales en la Hispania Céltica. BAR Publishing (BAR International Series 1963). Oxford.

Aranegui, C. (1997). Damas y caballeros en la ciudad ibérica. Cátedra (Historia. Serie Menor). Madrid.

Aranegui, C. (2004). Sagunto. Oppidum, emporio y municipio romano. Bellaterra. Barcelona.

Aranegui, C., Vives-Ferrándiz, J. (2006). Encuentros coloniales, respuestas plurales: los ibéricos antiguos de la fachada mediterránea central. En: De les comunitats locals als estats arcaics: la formació de les societats complexes a la costa del Mediterrani occidental. Universitat de Barcelona (Arqueo Mediterrània 9). Barcelona: 89-106.

Asensio, J. A. (1995). La ciudad en el mundo prerromano en Aragón. Institución Fernando el Católico (Caesaraugusta 70). Zaragoza.

Atrián, P. (1968). Una inscripción ibérica de 'El Palomar' de Oliete (Teruel). Teruel, 39: 117-119.

Ballester, X., Turiel, M. (2007). Posible inscripción hispanocéltica sobre fusayola. ELEA, 8: 37-41.

BARRANDON, N. (2011). De la pacification à l'intégration des Hispaniques (133-27 a. C.). Ausonius (Scripta Antiqua 35). Bordeaux.

Belarte, M. C., Garcia, D., Sanmartí, J. (eds.) (2015). Les estructures socials protohistòriques a la Gàl.lia $i$ a Ibèria. Homenatge a Aurora Martín i Enriqueta Pons. Universitat de Barcelona (Arqueo Mediterrània 14). Tarragona: 251-272.

Beltrán, A. (1958). Los hallazgos ibéricos de 'El Palomar', de Oliete (Teruel), y la Colección Orensanz, de Zaragoza. Caesaraugusta, 11-12: 25-32.

Beltrán, F. (1995), La escritura en la frontera, inscripciones y cultura epigráfica en el valle medio del Ebro. En: Beltrán, F. (ed.). Roma y el nacimiento de la cultura epigráfica en Occidente. Institución Fernando el Católico. Zaragoza: 69-195.
Beltrán, F. (2003). La romanización temprana en el valle medio del Ebro (siglos II-I a.E.): una perspectiva epigráfica. Archivo Español de Arqueología, 76: 179-191.

Beltrán, F. (2005). Cultura escrita, epigrafía y ciudad en el ámbito paleohispánico. Palaeohispanica, 5: 21-56.

Beltrán, F., Beltrán, M. (2012). Ama lateres! Sobre una pesa de telar cesaraugustana relativa al lanificium. Sylloge Epigraphica Barcinonensis, 10: 127-148.

Beltrán, F., Jordán, C., Simón, I. (e. p.). The inscriptions on pottery of Hispania Citerior $\left(2^{\text {nd }}-1^{\text {st }}\right.$ century BCE): A case study of the inscriptions on spindle whorls. En: Epigraphy on Ceramics.

Beltrán, F., Martín-Bueno, M., Pina, F. (2000). Roma en la cuenca media del Ebro. La romanización en Aragón. Caja de Ahorros de la Inmaculada (Mariano de Pano y Ruata 19). Zaragoza.

Beltrán, M. (1976). Arqueología e historia de las ciudades antiguas del Cabezo de Alcalá de Azaila (Teruel). Librería General (Monografías arqueológicas 19). Zaragoza.

Beltrán, M. (1995). Azaila. Nuevas aportaciones deducidas de la documentación inédita de Juan Cabré Aguiló. Institución Fernando el Católico. Zaragoza.

Beltrán, M. (1996). Los Iberos en Aragón. Caja de Ahorros de la Inmaculada (CAI 100, n. ${ }^{\circ} 81$ ). Zaragoza.

Beltrán, M. (2002). Sertorius dans la vallée de l'Ebre. Pallas, 60: 45-92.

Beltrán, M. (2013). Azaila. Estado de la cuestión en el año 2013 (contiene documentación inédita de Juan Cabré). Institución Fernando el Católico (Caesaraugusta 83). Zaragoza.

Binsfeld, W. (1997). Gefässnamen auf Keramik im Nordwesten des Römischen Reiches. Trierer Zeitschrift, 60: $19-31$.

Blasco, M. (2018). Una visión comparativa. Piezas de hueso, asta y otras materias primas de El Palomar (Oliete, Teruel). En: IX Jornadas de Jóvenes en Investigación Arqueológica. Instituto Internacional de Investigaciones Prehistóricas de Cantabria. Santander: 139-146.

Bonet, H. (1995). El tossal de San Miquel de Llíria. La antigua Edeta y su territorio. Servicio de Investigación Prehistórica. Valencia.

Bonet, H. (2013). Contextos arqueológicos de los textos ibéricos valencianos. Palaeohispanica, 13: 387-406.

Bonet, H., Grau, I., Vives-Ferrándiz, J. (2015). Estructura social y poder en las comunidades ibéricas de la franja central mediterránea. En: Belarte, M. C., 
GARcia, D., SANMARTí, J. (eds.), Les estructures socials protohistòriques a la Gàl.lia $i$ a Ibèria. Homenatge a Aurora Martín i Enriqueta Pons. Universitat de Barcelona (Arqueo Mediterrània 14). Tarragona: 251-272.

Bonet, H., Mata, C. (2002). El Puntal dels Llops. Un fortín edetano. Diputación de Valencia (Serie de Trabajos Varios 99). Valencia.

BožIČ, D., Feuguère, M. (2004). Les instruments de l'écriture. Gallia, 61: 21-65.

Burch, J. et alii (2001). Excavacions arqueològiques a la muntanya de Sant Julià de Ramis 1 El sector de l'antiga església parroquial. Sant Julià de Ramis. Girona.

Burillo, F. (1998). Los celtíberos. Etnias y estados. Crítica (Crítica Arqueológica). Barcelona.

Burillo, F. (2007). Espacio doméstico en la Celtiberia de los belos. En: Belarte, M. C. L'espai domèstic $i$ l'organització de la societat a la protohistòria de la Mediterrània occidental. Universitat de Barcelona (Arqueo Mediterrània 11). Barcelona: 165-188.

Burillo, F. (2007a). Los Celtíberos. Etnias y Estados. Crítica. Barcelona (segunda edición).

Burillo, F. (2009). Origen y desarrollo de la ciudad en la Celtiberia. En: Santuarios, oppida y ciudades. Arquitectura sacra en el origen y desarrollo urbano del Mediterráneo occidental. CSIC (E-Libro). Mérida: 175-193.

Burillo, F. (2011). Oppida, ciudades estado y populi en la transición del Ibérico Pleno al Tardío en el nordeste de la Península Ibérica. Ilercavònia, 3: 205-220.

Burillo, F. (2011a). Oppida y 'ciudades estado' celtibéricos. Complutum, 11: 277-295.

Burillo, F., Escolano, S., López, R., Ruiz, E. (2008). Roma versus Segeda. Una propuesta sobre el camino hispano seguido por el cónsul Nobilior en el año 153 a. C. Fundación Segeda (Estudios Celtibéricos. Serie Minor 3). Zaragoza.

Cabré, J. (1911). Catálogo Monumental de Teruel. Vol. I, inédito (el manuscrito está disponible en http:// biblioteca.cchs.csic.es/digitalizacion_tnt/index_interior_teruel.html).

Calbi, A., Donati, A., Poma, G. (eds.) (1993). L'epigrafia del villaggio. Fratelli Lega (Epigrafia e Antichità 12). Faenza.

Campmajo, P., Ferrer, J. (2010). Le nouveau corpus d'inscriptions ibériques rupestres de la Cerdagne (1): premiers résultats. Palaeohispanica, 10: 249-274.

Castro, Z. (1980). Fusayolas ibéricas, antecedentes y empleo. Cypsela, 3: 127-146.

CAT = Atrián, P., Escriche, C., Vicente, J., Herce, A. I. (1980). Carta Arqueológica de España. Teruel. Instituto de Estudios Turolenses. Zaragoza.
CNH = VIllaronga, L. (1994). Corpus nummum ante Augusti aetatem. José A. Herrero. Madrid.

DCPH = García-Bellido, M. P., Blázquez, C. (2001). Diccionario de cecas y pueblos hispánicos. CSIC (Textos Universitarios 36). Madrid.

De Hoz, J. (1995). Escrituras en contacto: ibérica y latina. En: Beltrán, F. (ed.). Roma y el nacimiento de la cultura epigráfica en Occidente. Institución Fernando el Católico. Zaragoza: 57-84.

De Hoz, J. (2007). Cerámica y epigrafía paleohispánica de fecha prerromana. Archivo Español de Arqueología, 80: $29-42$.

De Hoz, J. (2011). Historia lingüística de la península Ibérica en la Antigüedad II. El mundo ibérico prerromano y la indoeuropeización. CSIC (Manuales y anejos de Emérita LI). Madrid.

De Sus, M. L. (1986). Fusayolas del poblado celtibérico de Los Castellares (Herrera de la Navarros, Zaragoza). I. Tipología y función. Boletín del Museo de Zaragoza, 5: 183-208.

Díaz, B., Mayayo, A. (2008). Cuatro nuevos grafitos ibéricos procedentes de Azaila. Palaeohispanica, 8: 197-202.

Evans, J. (1987). Graffiti and the Evidence of Literacy and Pottery use in Roman Britain. Archaeological Journal, 144: 191-204.

FARIA, A. M. (1994). Subsídios para o estudo da antroponímia ibérica. Vipasca, 3: 65-71.

FAtÁs, G. (1980-1981). Romanos y celtíberos citeriores en el siglo I antes de Cristo. Caesaraugusta, 51-54: 195-234.

FatÁs, G., Beltrán, M. (1997). Historia de Zaragoza. Salduie, ciudad ibérica. Ayuntamiento de Zaragoza (Historia de Zaragoza 1). Zaragoza.

Ferrer, J. (2005). Novetats sobre el sistema dual de diferenciació gràfica de les oclusives sordes i sonores. Palaeohispanica, 5: 957-982.

FERrer, J. (2008). Ibèric kaśtaun: un element característic del lèxic sobre torteres. Cypsela, 17: 253-271.

FERrer, J. (2014). Ibèric kutu i els abecedaris ibèrics. Veleia, 31: 227-259.

Ferrer, J., Garcés, I. (2005). El plom ibèric d'Olriols (Sant Esteve de Llitera, Osca). Palaeohispanica, 5: 983-994.

Ferrer, J., SÀnchez, M. (2017). L'enigma B'oïde al descobert: kaśtaum i baikar en sengles inscripcions ibèriques sobre una tortera $\mathrm{i}$ un vaset de Camps de l'Hospital (Vilademuls). Revista d'Arqueologia de Ponent, 27: 221-236. 
Ferrer, J., Asensio, D., Pons. E. (2014-2016). Novetats epigràfiques ibèriques dels segles V-IV aC del Mas de Castellar (Pontós, Alt Empordà). Cypsela, 20: 117-139.

Fletcher, D. (1972). Nuevas inscripciones ibéricas de la región valenciana. Archivo de Prehistoria Levantina, 13: $103-126$.

Fragmentos de Historia = Escriche, C., Ezouerra, B. (coords.) (2007). Fragmentos de Historia. 100 años de arqueología en Teruel. Museo de Teruel. Teruel.

Galiay, J. (1951). Excavaciones en El Palomar (OlieteTeruel). Caesaraugusta, 1: 35-36.

Galve, M. P. (1996). Los antecedentes de Caesaraugusta. Estructuras domésticas de Salduie (calle Don Juan de Aragón 9, Zaragoza). Institución Fernando el Católico. Zaragoza.

Gómez Moreno, M. (1948). Suplemento de epigrafía ibérica. En: Gómez Moreno, M. Misceláneas. Dispersa, emendata, inedita. CSIC. Madrid: 31-73.

Gorgues, A., Moret, P., Ruiz-Darasse, C. (2003). Cinq nouvelles inscriptions sur céramique du bas Aragon et de la Terra Alta. Palaeohispanica, 3: 245-250.

Gorgues, A. (2009). L'epigraphie dans l'atelier de potiers du Mas de Moreno (Foz-Calanda, Teruel): la structure de la production à l'époque ibérique tardive (II ${ }^{\mathrm{e}} \mathrm{I}^{\mathrm{er}}$ S. AC). Palaeohispanica, 9: 481-500.

GuÉRIN, P., SiLgO, L. (1996). Inscripción ibérica sobre plomo de Castellet de Bernabé (Llíria, Valencia). Revista d'Arqueologia de Ponent, 6: 199-206.

Harris, W. V. (1989). Ancient Literacy. Harvard University Press. London.

Hilgers, W. (1969). Lateinische Gefässnamen. Bezeichnungen, Funktion und Form römischer Gefässe nach den antiken Schriftquellen. Bonner Jahrbücher des Rheinischen Landesmuseums in Bonn. Düsseldorf.

IzQuiERDo, I. (2001). La trama del tejido y el vestido femenino en la cultura ibérica. En: Martín, M. (ed.). Tejer y vestir de la Antigüedad al Islam. CSIC. Madrid: 287-312.

Izquierdo, I., Pérez Ballester, J. (2005). Grupos de edad y género en un nuevo vaso del Tossal de Sant Miquel de Llíria (Valencia). Saguntum, 37: 85-103.

LAmbert, P. Y. (2002). Recueil des inscriptions gauloises II.2. Textes gallo-latins sur instrumentum. CNRS. Paris.

Llobregat, E. (1972). Contestania ibérica. Universidad de Alicante. Alicante.

Loscos, R. M., Martínez, M. R., Herreo, M. A. (2007). El Castelillo (Alloza, Teruel). En: Ezouerra, B., Herce, A. I. (eds.). Fragmentos de historia. 100 años de arqueología de Teruel. Museo de Teruel. Teruel: 177-180.
Maestro, E. (1989). Cerámica ibérica decorada con figura humana. Universidad de Zaragoza. Zaragoza.

Magallón, M. A. (1987). La red viaria romana en Aragón. Diputación General de Aragón (Estudios y monografías 3). Zaragoza.

Maluquer, J. (1968). Epigrafía prelatina de la Península Ibérica. Universidad de Barcelona (Publicaciones Eventuales 12). Barcelona.

Martí, M. A. (1998). El área territorial de Arse-Saguntum en época ibérica. Institució Alfons El Magnànim (Estudios Universitarios 72). Valencia.

Mata, C. (1997). La ciudad ibérica de Edeta y sus hallazgos arqueológicos. En: Aranegui, C. (ed.). Damas y caballeros en la ciudad ibérica. Cátedra. Madrid: $15-48$.

Mata, C. (2001). Límites y fronteras en Edetania. Archivo de Prehistoria Levantina, 24: 243-272.

MLH = UntermanN, J. (1975-1997). Monumenta Linguarum Hispanicarum (Ludwig Reichert). Wiesbaden.

Moncunill, N. (2007). Lèxic d'inscripcions ibèriques (1991-2006). Barcelona (tesis doctoral).

Moret, P. (1996). Les fortifications ibériques, de la fin de l'âge du bronze à la conquête romaine. Casa de Velázquez (Collection de la Casa de Velázquez 56). Madrid.

Moret, P. (2005). Ibérisation archéologique, ibérisation linguistique: le cas du Bas Aragon. Palaeohispanica, 5: 273-294.

Moret, P., Benavente, J. A., Gorgues, A. (2006). Iberos del Matarraña. Investigaciones arqueológicas en Valdetormo, Calaceite, Cretas y La Fresneda (Teruel). Taller de Arqueología de Alcañiz (Al-Qannis 11). Alcañiz.

Olmos, R. (1987). Posibles vasos de encargo en la cerámica ibérica del Sureste. Archivo Español de Arqueología, 60: 21-42.

Orensanz, F. (1975-1976). Aportación al estudio del despoblado ibérico de San Pedro (Oliete, Teruel). Caesaraugusta, 39-40: 175-186.

Panosa, M. I. (1999). La escritura ibérica en Cataluña y su contexto socioeconómico (siglos $V-I$ a. C.). Universidad del País Vasco (Veleia. Anejos Minor 13). Vitoria.

Prosdocimi, A. L. (1990). Insegnamento e apprendimento della scrittura nell'Italia antica. En: PANDOLFINI, M., Prosdocimi, A. L. Alfabetari e insegnamento della scrittura in Etruria e nell'Italia antica. Leo S. Olschki (Biblioteca di Studi Etruschi). Firenze: 155-301.

Raybould, M. E. (1999). A Study of Inscribed Material from Roman Britain. An inquiry into some aspects of literacy in Roman-British society. University of Oxford (BAR 281). Oxford. 
Ripoll, E. (1955). Noticias de poblados del NE. de la provincia de Teruel. Teruel, 13: 117-137.

Rodríguez Blanco, J. (1977). Relación campo-ciudad y organización social en la Celtiberia Ulterior (s. II a. C.). Memorias de Historia Antigua, 1: 167-178.

Rodríguez Ramos, J. (2001). Signos de lectura problemática en la escritura ibérica. Archivo Español de Arqueología, 74: 281-290.

Rodríguez Ramos, J. (2002). Índice crítico de formantes de compuesto de tipo onomástico en la lengua íbera. Cypsela, 14: 251-275.

Rodríguez Ramos, J. (2002-2003). ¿Existe el doble sufijo de 'genitivo' -ar-en en la lengua íbera? Quaderns de Prehistòria i Arqueologia de Castelló, 23: 251-255.

Rodríguez Ramos, J. (2004). Análisis de epigrafía íbera. Universidad del País Vasco (Veleia. Anejos. Series Minor 22). Vitoria.

RodRíGuez Ramos, J. (2005-2006). Observaciones sobre algunas inscripciones ibéricas. Kalathos, 24-25: 461-473.

Rodríguez Ramos, J. (2014). Nuevo Índice Crítico de formantes de compuestos de tipo onomástico íberos. ArqueoWeb, 15: 81-238.

Ruiz, C., Simón, I. (2012). Novedades epigráficas y reflexiones metodológicas sobre contactos de lenguas en el Ibérico Final. En: Iberos del Ebro. Actas del II Congreso Internacional. Institut Català d'Arqueologia Clàssica (Documenta 25). Tarragona: 345-358.

SALVAT, E. (2005). La tècnica de l'estampillat a l'epigrafia ibèrica i celtibèrica. Sylloge Epigraphica Barcinonensis, 5: 149-171.

SAnZ, M. (2014). El signo T en las escrituras ibérica y celtibérica. Palaeohispanica, 14: 129-152.

SARRIón, I. (2003). Dos nuevas inscripciones ibéricas del Castellet de Bernabé. En: GuéRin, P. El Castellet de Bernabé y el horizonte ibérico pleno edetanos. Diputación de Valencia (Serie de Trabajos Varios 101). Valencia: 363-368.

Silgo, L. (1999). Cuatro grafitos de El Palomar (Oliete) en el Museo de Teruel. Cauce, 3: 26-31.

Silgo, L. (2001). Grafitos ibéricos de El Palomar (Oliete, Teruel). Palaeohispanica, 1: 347-352.

Simón, I. (2008). Dos estampillas inscritas sobre pesas de telar de la colección Samitier. Palaeohispanica, 8: 257-278.

Simón, I. (2010). Ilturbilos, un antropónimo ibérico en El Palomar de Oliete (Teruel). Saguntum, 42: 119-122.

Simón, I. (2012). Revisión de epigrafía ibérica turolense. Zephyrus, 69: 199-211.

Simón, I. (2012a). Epigrafía ibérica en espacios domésticos. Antesteria, 1: 267-282.
Simón, I. (2012b). Un grafito ibérico sobre una pesa de telar de La Guardia de Alcorisa (Teruel). Habis, 43: 73-82.

Simón, I. (2012c). La epigrafía ibérica de Montaña Frontera. Madrider Mitteilugen, 53: 239-260.

Simón, I. (2013). Los soportes de la epigrafía paleohispánica. Inscripciones sobre piedra, bronce y cerámica. Prensas de la Universidad de Zaragoza - Secretariado de Publicaciones de la Universidad de Sevilla (Ciencias Sociales 91). Zaragoza-Sevilla.

Simón, I. (2013a). El final de las escrituras paleohispánicas. Palaeohispanica, 13: 167-186.

Simón, I. (2016). El esclavo refugiado en el altar: una escena de la comedia griega en un entalle del Palomar de Oliete (Teruel). En: Lorenzo, J. I., RoDANÉs, J. M. (eds.). I Congreso Capa. Arqueología y patrimonio aragonés. Colegio Oficial de Doctores y Licenciados en Filosofía y Letras y en Ciencias de Aragón. Zaragoza: 383-388.

Simón, I. (e. p.). Epigrafía ibérica de Teruel 19902012). Teruel, en prensa.

Simón, I. (e. p. a). Los estilos de hueso en los yacimientos del valle medio del Ebro. Un elemento novedoso en la cultura material de los siglos II y I a. C. En: Uroz, H., Ribera, A. (eds.). Cultura material romana en la Hispania republicana.

Sinner, A. G., Ferrer, J. (2016). Del oppidum de Burriac a las termas de Ca l'Arnau. Una aproximación a la lengua y a la identidad de los habitantes de Ilduro (Cabrera de Mar, Badalona). Archivo Español de Arqueología, 89: 193-223.

Untermann, J. (2001). Algunas novedades sobre la lengua de los plomos ibéricos. En: Villar, F., FERNÁNDez Álvarez, M. P. (eds.). Religión, lengua y cultura prerromanas de Hispania. Universidad de Salamanca (Acta Salmanticensia. Estudios filológicos). Salamanca: 613-627.

Vegas, M. (1973). Cerámica común romana del Mediterráneo Occidental. Universidad de Barcelona. Barcelona.

Velaza, J. (1991). Léxico de inscripciones ibéricas 1976-1989. Bellaterra. Barcelona.

Velaza, J. (2002). Las inscripciones monetales. En: Ripollès, P. P., Llorens, M. M. Arse-Saguntum. Historia monetaria de la ciudad y su territorio. Fundación Bancaja. Sagunto: 121-148.

Velaza, J. (2012). La escritura de lo sagrado en el mundo ibérico. En: Diálogo de identidades. Bajo el prisma de las manifestaciones religiosas en el ámbito mediterráneo (s. III a. C. - s. I. d. C.). CSIC (Anejos de Archivo Español de Arqueología 72). Mérida: 159-166.

Velaza, J. (2012a). Inscripciones paleohispánicas con signarios: formas y funciones. ELEA, 12: 151-165. 
Vicente, J., Escriche, C., Punter, M. P. (1985). Las construcciones defensivas del poblado ibérico del 'Cabezo de San Pedro' (Oliete, Teruel). Boletín del Museo de Zaragoza, 4: 63-93.

Vicente, J. (1981). Informe sobre las excavaciones arqueológicas realizadas en El Palomar de Oliete durante 1981. Teruel, 66: 318-319.

VicEnTE, J. (1982). Excavaciones arqueológicas realizadas en El Palomar (Oliete) durante 1982. Teruel, 68: $259-263$.

Vicente, J. (2007). El poblado ibérico de 'El Palomar'. En: Fragmentos de Historia. 100 años de arqueología en Teruel. Museo de Teruel. Teruel: 186-190.

Vicente, J. (2007a). La fortificación ibérica del Cabezo de San Pedro (Oliete, Teruel). En: Fragmentos de Historia. 100 años de arqueología en Teruel. Museo de Teruel. Teruel: 181-185.
Vicente, J., Ezquerra, B., Escriche, C. (1990). En Oliete hace dos mil años. Museo de Teruel. Teruel.

Villaronga, L. (2004). Numismàtica antiga de la Península Ibèrica. Introducció al seu estudi. Societat Catalana d'Estudis Numismàtics. Barcelona.

Werner, S. (2009). Literacy Studies in Classics. En: Johnson, W. A., Parker, H. N. (eds.). Ancient literacies: the culture of reading in Greece and Rome. New York Oxford University Press. Oxford-New York: 333-382.

Woolf, G. (2000). Literacy. En: The Cambridge Ancient History 11. Cambridge University Press. Cambridge: 875-897.

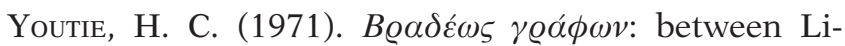
teracy and Illiteracy. Greek, Roman and Byzantine Studies, 12.2: 239-261.

Youtie, H. C. (1975). Because they do not know letters. Zeitschrift für Papyrologie und Epigraphik, 19: 101-108. 